\title{
Carboxybetaine, Sulfobetaine, and Cationic Block Copolymer Coatings: A Comparison of the Surface Properties and Antibiofouling Behavior
}

\author{
Lin $\mathrm{Wu}^{1}{ }^{1}$ Jacek Jasinski, ${ }^{2}$ Sitaraman Krishnan ${ }^{1}$ \\ ${ }^{1}$ Department of Chemical and Biomolecular Engineering, Clarkson University, Potsdam, New York 13699 \\ ${ }^{2}$ Conn Center for Renewable Energy Research, University of Louisville, Louisville, Kentucky 40292
}

Received 1 June 2011; accepted 10 July 2011

DOI 10.1002/app.35233

Published online 26 October 2011 in Wiley Online Library (wileyonlinelibrary.com).

\begin{abstract}
Two different zwitterionic block copolymers (BCs) and a cationic BC were synthesized from the same BC precursor, which consisted of a polystyrene (PS) block and a poly[N-(3-dimethylamino-1-propyl)acrylamide] block. The zwitterionic $\mathrm{BCs}$ contained the dimethylammonioacetate (carboxybetaine) and dimethylammoniopropyl sulfonate (sulfobetaine) groups. Thin films cast from these polymers were investigated for surface wettability, surface charge, and protein adsorption. Surface-energy parameters calculated with advancing contact angle $\left(\theta_{a}\right)$ and receding contact angle $\left(\theta_{r}\right)$ of different probe liquids showed that it was $\theta_{r}$ and not $\theta_{a}$ that was representative of the polar/ionic groups in the near-surface regions of the coatings. Electrophoretic mobility was used to characterize the influence of $\mathrm{pH}$ on the net surface charge. In aqueous dispersions, the carboxybetaine polymer showed an ampholyte behavior with an isoelectric point of 6 , whereas the sulfobetaine polymer was found to be anionic at all $\mathrm{pH}$ values between 2 and 10. Protein adsorption
\end{abstract}

on the carboxybetaine $\mathrm{BC}$ was relatively independent of the net charges on the protein or the polymer, but the negatively charged sulfobetaine polymer showed a higher adsorption of positively charged protein molecules. Regardless of the net protein charge, both zwitterionic coatings adsorbed less protein compared to the PS and poly(2,3,4,5,6-pentafluorostyrene) controls. The sulfobetaine and cationic BCs adsorbed higher amounts of oppositely charged protein molecules than like-charged protein molecules. However, the adsorption of oppositely charged protein was much higher on the cationic surface than on the sulfobetaine surface. The zwitterionic BCs, particularly the carboxybetaine polymer, from this article are expected to function as stable, low-fouling surface modifiers in different biological environments. () 2011 Wiley Periodicals, Inc. J Appl Polym Sci 124: 2154-2170, 2012

Key words: biomaterials; block copolymers; coatings; hydrophilic polymers; ionomers

\section{INTRODUCTION}

Protein- and cell-repellant polymers are important in the surface modification of biomaterials and biosensors and in ultrafiltration and marine antifouling technologies. ${ }^{1-8}$ Hydrophilic coatings, such as those prepared with nonionic poly(ethylene glycol) (PEG) containing polymers, have been widely studied. ${ }^{9-11}$ On the basis of these studies, it has become evident that a high degree of hydration and conformational flexibility are important attributes of a protein-repellant polymer surface. In recent years, there has been a significant interest in the use of ionic polymers for antifouling surfaces because of the ability of ions to bind water molecules. Ionic polymers have also been explored for biomedical uses, for example, in bactericidal coatings, ${ }^{5,12}$ coatings for tissue culture sub-

Correspondence to: S. Krishnan (skrishna@clarkson.edu).

Contract grant sponsor: Army Research Office; contract grant number: W911NF-05-1-0339.

Journal of Applied Polymer Science, Vol. 124, 2154-2170 (2012) (c) 2011 Wiley Periodicals, Inc. strates, and coatings for drug delivery and gene delivery. ${ }^{2}$

Zwitterionic molecules are particularly relevant in applications where protein adsorption and cell adhesion to synthetic surfaces must be prevented. ${ }^{13}$ Zwitterions are dipolar ions, or charge-separated ions, wherein the charges are usually separated by distances greater than one bond length. Unlike salts, which contain dissociable ions, the cationic and anionic centers in a zwitterion do not dissociate (i.e., split in to separate cations and anions). In the aqueous phase, zwitterions strongly interact with dipolar water through charge-dipole interactions and are, therefore, highly hydrated.

Several studies in the past have used ultrathin coatings of either self-assembled monolayers or polymer brushes (of ionic or polar molecules) to prepare antibiofouling surfaces. ${ }^{14}$ The surface-tethering of these molecules with thiolate, siloxane, or phosphonate linkages prevents their dissolution in an aqueous environment. However, a thickness of several micrometers is usually necessary for a polymer to function as a protective coating in demanding applications such as marine antifouling paints. The 
use of block copolymers (BCs) and a bilayer coating strategy, which was described previously, ${ }^{11}$ is a promising approach toward designing such coatings. The BCs are tailored to have a water-insoluble block, such as polystyrene (PS), and an antibiofouling, surface-active block. Because of the surface-active block, when the BC is blended with a relatively inexpensive thermoplastic elastomer such as polystyreneblock-poly(ethylene-ran-butylene)-block-polystyrene (SEBS), it spontaneously migrates to the surface of the coating to result in a self-healing, protective, antifouling surface.

\section{Protein adsorption}

One of the objectives of this study was to compare the antifouling properties of novel zwitterionic BCs containing carboxybetaine and sulfobetaine groups with those of a cationic polymer. Zwitterionic coatings, which mimic the biocompatibility of the extracellular surfaces of plasma membranes, ${ }^{15}$ have been found to be quite effective in preventing protein adsorption on synthetic surfaces. ${ }^{13}$ Using neutron reflectivity measurements, Murphy et al. ${ }^{16}$ found that the top $2.5 \mathrm{~nm}$ of a copolymer thin film containing the zwitterionic phosphoryl choline group consisted of approximately $85 \%$ water. The high degree of hydration of the phosphoryl choline layer created a steric barrier that prohibited protein adsorption. Homopolymer brushes of zwitterionic monomers containing $\mathrm{N}, \mathrm{N}$-dimethylammoniopropyl sulfonate and $\mathrm{N}, \mathrm{N}$-dimethylammoniopropionate have been well-documented for their antifouling properties. ${ }^{17-24}$

According to the Derjaguin-Landau-VerweyOverbeek theory, electrostatic and van der Waals forces are the two important intermolecular forces that determine protein-surface interactions. Electrostatic interactions depend on the surface potential, net charge, and distribution of charge on the protein surface and the ionic strength of the aqueous phase. Protein charge is determined by the $\mathrm{pH}$ of solution and the isoelectric point of the protein. Roth and Lenhoff ${ }^{25}$ showed that the contribution of electrostatic attraction to the lowering of free energy when a protein interacts with a surface is significantly higher than the van der Waals contribution, even when the surface charge density is very low. Electrostatic interactions have been found by several researchers to play an important role in protein adsorption. ${ }^{26-36}$

To our knowledge, there are few reports on the synthesis, surface characterization, and antibiofouling properties of ionic BCs. Moreover, the $\mathrm{pH}$-dependent amphoteric behaviors of carboxybetaine and sulfobetaine polymers are not well understood. The objectives of the work reported herein were twofold: (1) to synthesize new protein-resistant ionic
BCs, which could be used to create self-healing elastomeric antifouling paints, and (2) to conduct a detailed study of wettability, surface charge, and protein repellency of the surfaces of these ionic copolymers. Films of zwitterionic and cationic BCs were obtained by the spin-coating of the polymers on glass or silicon substrates. The surface wettability of these films was characterized with dynamic contact angle measurements. The influence of the ionic groups on the dispersion and polar components of surface energy were investigated with different surface energy models available in the literature. X-ray photoelectron spectroscopy (XPS) was used to determine the surface composition of the BC films. Fluorescence microscopy was used to characterize the protein adsorption on the BC surfaces. Surface charges were characterized with $\zeta$-potential measurements, and the influence of the net charges of the protein molecule and the $\mathrm{BC}$ surfaces on protein adsorption was investigated. Protein adsorption on the ionic BCs was compared with those on PS and a relatively hydrophobic fluoropolymer, poly(2,3,4,5,6pentafluorostyrene) (PPFS).

\section{EXPERIMENTAL}

\section{Materials}

Styrene (CAS no. 100-42-5, Sigma-Aldrich, Milwaukee, WI, $\geq 99 \%$ ), tert-butyl acrylate (CAS no. 166339-4, Aldrich, Milwaukee, WI, 98\%), and 2,3,4,5,6pentafluorostyrene (PFS; CAS no. 653-34-9, Matrix Scientific, Columbia, SC, 99\%) were treated with neutral alumina to remove the inhibitor. $\mathrm{CuBr}$ (CAS no. 7787-70-4, Aldrich, Milwaukee, WI, 99.999\%), $\mathrm{CuBr}_{2}$ (CAS no. 7789-45-9, Aldrich, Milwaukee, WI, 99\%), $N, N, N^{\prime}, N^{\prime \prime}, N^{\prime \prime}$-pentamethyldiethylenetriamine (CAS no. 3030-47-5, Aldrich, Allentown, PA, 99\%), methyl-2-bromopropionate (CAS no. 5445-17-0, Aldrich, Milwaukee, WI, 98\%), 3-(dimethylamino)-1propylamine (CAS no. 109-55-7, TCI America, Portland, OR, $\geq 99 \%$ ), 2,2-azobis(2-methylpropionitrile) (AIBN; CAS no. 78-67-1, Aldrich, Milwaukee, WI, 98\%), 4-(dimethylamino)pyridine (DMAP; CAS no. 1122-58-3, Fluka, Allentown, PA, $\geq 99 \%$ ), N-(3-dimethylaminopropyl)acrylamide (DMAPrAAm; CAS no. 3845-76-9, TCI America, Portland, OR, $>98 \%$ ), $N, N^{\prime}-$ diisopropylcarbodiimide (DIC; CAS no. 693-13-0, Aldrich, Milwaukee, WI, 99\%), 1,3-propanesultone (CAS no. 1120-71-4, TCI America, Portland, OR, > 99\%), 2-bromoacetic acid (CAS no. 79-08-3, Alfa Aesar, Ward Hill, MA, > 98\%), methyl bromoacetate (CAS no. 96-35-2, Alfa Aesar, > 98\%), Zonyl FSO$100\left[\mathrm{R}_{\mathrm{f}} \mathrm{PEG}-\mathrm{OH}\right.$, where $\mathrm{R}_{\mathrm{f}} \mathrm{PEG}$ is $\omega$-perfluoroalkyl poly(ethylene glycol), CAS no. 65545-80-4, Aldrich, Milwaukee, WI], sodium salt of ethylene diamine tetraacetic acid (CAS no. 10378-23-1, Fisher Scientific, 
Fair Lawn, NJ), and Supelco Amberlite IRA-400 $\left(\mathrm{OH}^{-}\right)$anion-exchange resin (16-50 mesh, SigmaAldrich, Milwaukee, WI) were used as received. Fluorescein isothiocyanate conjugated bovine serum albumin (BSA-FITC), phosphate-buffered saline (PBS) tablets, and 4-morpholineethanesulfonic acid (MES; CAS no. 4432-31-9, $\geq 99.5 \%$ ) were purchased from Sigma and were used without further purification. In BSA-FITC, the extent of labeling was at least seven fluorescein isothiocyanate (FITC) molecules per molecule of bovine serum albumin (BSA). The fluorophore had an excitation peak wavelength of about $495 \mathrm{~nm}$ and an emission peak wavelength of about $521 \mathrm{~nm}$. The PBS solution ( $\mathrm{pH}$ of about 6.9 at $25^{\circ} \mathrm{C}$ ) consisted of $137 \mathrm{mM} \mathrm{NaCl}, 2.7 \mathrm{mM} \mathrm{KCl}, 10$ $\mathrm{mM} \mathrm{Na}_{2} \mathrm{HPO}_{4}$, and $2 \mathrm{mM} \mathrm{KH} \mathrm{PO}_{4}$ in distilled water. A MES solution of $50 \mathrm{mM}$ concentration was prepared in water. The $\mathrm{pH}$ of this solution was about $3.5 \pm 0.2$ (consistent with a $\mathrm{p} K_{a}$ of 6.1 at $25^{\circ} \mathrm{C}$ ). Solvents such as $\mathrm{N}, \mathrm{N}$-dimethylformamide (DMF; J. T. Baker (Avantor Performance Materials), Phillipsburg, $\mathrm{NJ})$, pyridine (J. T. Baker), dichloromethane $\left(\mathrm{CH}_{2} \mathrm{Cl}_{2}\right.$, J. T. Baker), dioxane (Acros, > 99.9\%), diethyl ether $\left(\mathrm{Et}_{2} \mathrm{O}, \mathrm{J}\right.$. T. Baker), hexanes (J. T. Baker), and tetrahydrofuran (THF; CAS no. 109-99-9, Sigma-Aldrich, Milwaukee, WI, $\geq 99.9 \%$, anhydrous), unless specified, were used as received. Solvents for the reactions were dried with type $3 \mathrm{~A}$ molecular sieves (Fluka, Allentown, PA). Glycerol (CAS no. 56-81-5, EMD Chemicals, Gibbstown, NJ, > 99.5\%), 1-bromonaphthalene (CAS no. 90-11-9, Alfa Aesar, 97\%), hexadecane (CAS no. 544-76-3, J. T. Baker, > 99\%), diiodomethane (CAS no. 75-11-6, Alfa Aesar, 99\%), ethylene glycol (CAS no. 107-21-1, Sigma-Aldrich, Milwaukee, WI, 98\%, anhydrous), and dimethyl sulfoxide (CAS no. 67-68-5, J. T. Baker, 99.9\%) were stored in a desiccator and used for contact angle measurements. Distilled water and ultrapure nitrogen were used throughout.

\section{Methods}

Gel permeation chromatography of THF solutions of the polymers was carried out with a 515 HPCL pump (Waters Corporation, Milford, MA) operating at room temperature, two PLgel Mixed-C columns (Agilent Technologies, Santa Clara, CA), and a Viscotek model LR40 laser refractometer (Malvern Instruments, Westborough, MA). The columns were calibrated with commercial linear PS and poly (methyl methacrylate) standards. The IR spectra of the polymers cast as films from chloroform solutions on $\mathrm{NaCl}$ or $\mathrm{KBr}$ salt plates were collected with a Spectrum 100 Fourier transform infrared (FTIR) spectrometer (PerkinElmer, Waltham, MA). ${ }^{1} \mathrm{H}-\mathrm{NMR}$ spectra were recorded on a $400 \mathrm{MHz}$ Bruker Avance DMX-400 nuclear magnetic resonance spectrometer
(Bruker Biospin, Billerica, MA) at ambient temperature in deuterated solvents.

The surfaces for contact angle measurement and protein adsorption studies were prepared on $1.8 \times$ $1.8 \mathrm{~cm}^{2}$ glass slides (Fisherfinest Premium Cover Glasses, Fisher Scientific, Fairlawn, NJ). The polymer solution $(3 \% \mathrm{w} / \mathrm{v})$ was spin-coated on the glass slides with a model WS-400-6NPP-LITE spin coater (Laurell Technologies, North Wales, PA) at $2000 \mathrm{rpm}$ for $1 \mathrm{~min}$. The surfaces were dried at $60^{\circ} \mathrm{C}$ for $24 \mathrm{~h}$ before they were further annealed at $120^{\circ} \mathrm{C}$ in a vacuum oven for $24 \mathrm{~h}$. Room-temperature contact angles were measured by the sessile drop method with a model 100-00 Ramé-Hart Instrument Co. (Netcong, NJ) contact angle goniometer and a 22gauge stainless steel needle $(0.7 \mathrm{~mm}$ o.d. and 0.4 $\mathrm{mm}$ i.d.). Dynamic water contact angle measurements were performed by the addition and retraction of a drop of solvent on the surfaces.

BSA-FITC was used to study protein interaction with the BC surfaces. The substrates were incubated in a $100 \mu \mathrm{g} / \mathrm{mL}$ solution of BSA-FITC in a PBS solution $(\mathrm{pH} \approx 6.9)$ in the dark for $60 \mathrm{~min}$. Then, the substrates were gently rinsed five times with PBS with a 2-mL Pasteur pipette and observed under a fluorescence microscope. The polymer films were also incubated in a $100 \mu \mathrm{g} / \mathrm{mL}$ solution of BSAFITC in MES solution ( $\mathrm{pH} 3.5$ at $25^{\circ} \mathrm{C}$ ) and analyzed for BSA-FITC adsorption, as in the case of PBS. Fluorescence microscopy was performed using an Olympus BX51 microscope (Olympus America, Melville, NY) with a U Plan Fluorite $40 \times$ dry objective. Images were acquired with a Photometrics (Tucson, AZ) CoolSNAP ES camera and Meta Imaging Series 6.1 software (Universal Imaging Corporation, West Chester, PA). FITC was observed with a $450-\mathrm{nm}$ excitation and 550-nm emission filter set. The fluorescence intensity, which was proportional to the surface density of the adsorbed protein, was quantified with ImageJ software (National Institute of Mental Health, Bethesda, MD).

For $\zeta$-potential measurements, solutions of BSA $(25 \mu \mathrm{g} / \mathrm{mL})$ were prepared in PBS and MES solutions ( $\mathrm{pH} 6.9$ and 3.5, respectively). The $\zeta$ potential of the protein in these solutions was measured at room temperature with a ZetaPlus $\zeta$-potential analyzer (Brookhaven Instruments, Holtsville, NY). The instrument used electrophoretic light scattering for mobility measurements. The Helmholtz-Smoluchowski equation $\left[\mu_{e}=\varepsilon_{0} \varepsilon_{r} \zeta / \eta\right.$, where $\mu_{e}$ is the electrophoretic mobility $\left(\mathrm{m}^{2} \mathrm{~V}^{-1} \mathrm{~s}^{-1}\right), \varepsilon_{0}$ is the vacuum permittivity $\left(8.85 \times 10^{-12} \mathrm{C}^{2} \mathrm{~J}^{-1} \mathrm{~m}^{-1}\right), \quad \varepsilon_{r}$ is the dielectric constant of the medium (78.54 for water at $\left.25^{\circ} \mathrm{C}\right), \zeta$ is the $\zeta$ potential $(\mathrm{V})$, and $\eta$ is the viscosity of the medium $\left(8.937 \times 10^{-4} \mathrm{~Pa} \mathrm{~s}\right.$ for water at $\left.\left.25^{\circ} \mathrm{C}\right)\right]$ was used to convert mobilities to $\zeta$ potentials. ${ }^{37} \mathrm{Col}-$ loidal particles were prepared from the ionic BCs by 


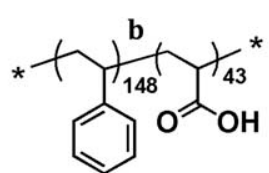

(1)
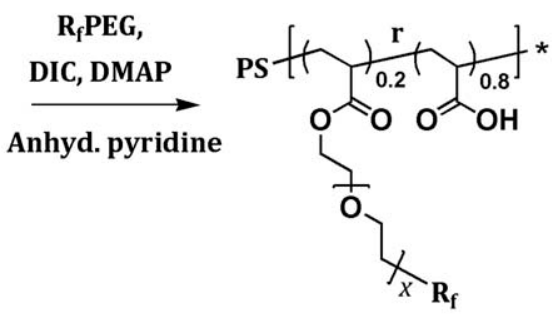

Precursor BC, 2

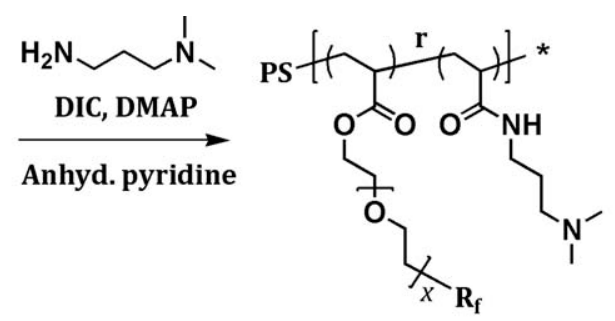

(2)

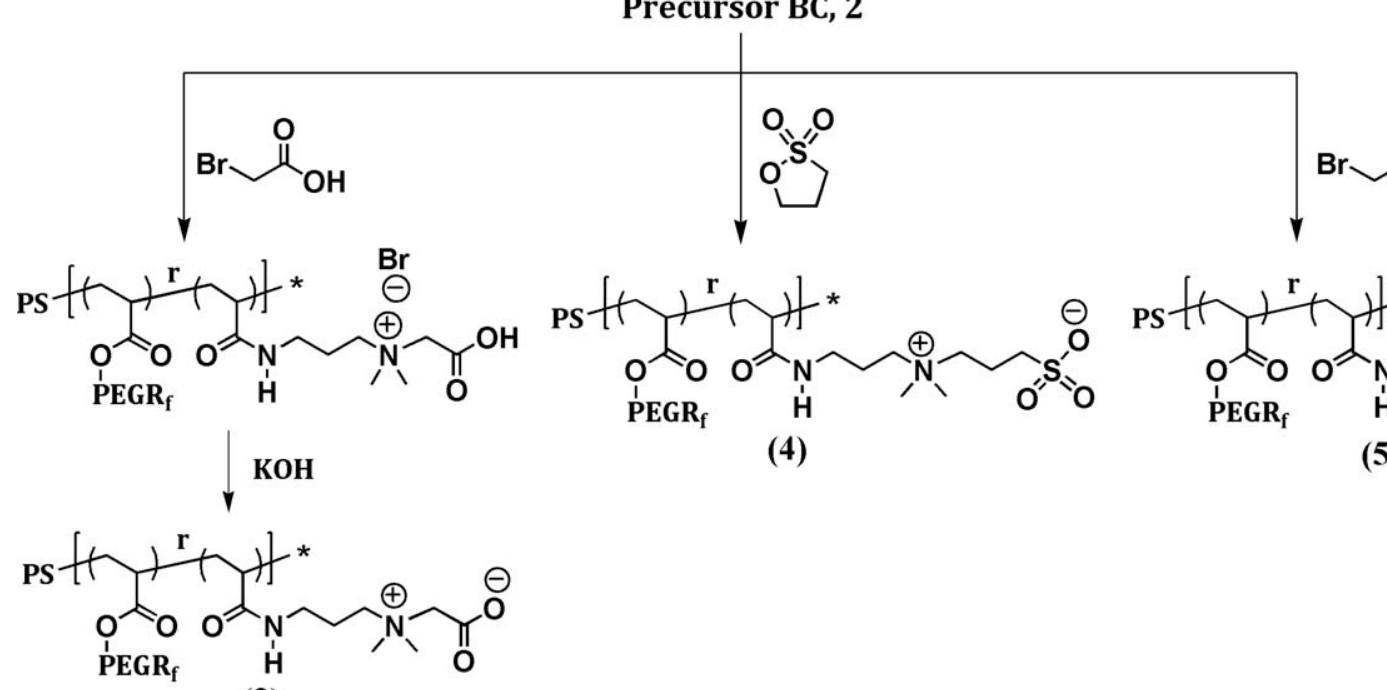

(3)

Scheme 1 Synthesis of the N-(3-dimethylamino-1-propyl)acrylamide BC precursor, and the zwitterionic and cationic BCs.

dispersion of the BCs $(90 \mathrm{mg})$ in THF $(1 \mathrm{~mL})$, addition of the dispersion to distilled water $(30 \mathrm{~mL})$, and distilling off the THF in vacuo at about $50^{\circ} \mathrm{C}$. The $\mathrm{pH}$ values of the resulting dispersions were adjusted with hydrochloric acid and potassium hydroxide solutions.

XPS spectra were acquired using a VG Microtech (West Sussex, UK) Multilab ESCA 3000 spectrometer equipped with a dual-anode $(\mathrm{Mg} / \mathrm{Al})$ X-ray source operated at about $33 \mathrm{~W}$ and a VG-CLAM4 hemispherical electron energy analyzer (VG Microtech) with a nine-channel array detector. Nonmonochromatized $\mathrm{Mg} \mathrm{K} \alpha$ X-ray beam $(h v \approx 1253.6 \mathrm{eV}$ ) was used. The high-resolution $C 1$ s spectra reported here were acquired at an electron emission angle $(\phi)$ of $55^{\circ}$ relative to the surface normal. The spectra were analyzed with CasaXPS version 2.3.14 software (Casa Software Ltd.). We performed binding energy calibration by setting the position of the $\mathrm{C}-\mathrm{C}$ peak to a binding energy of $285.0 \mathrm{eV}$.

\section{Synthesis of the surface-active cationic and} zwitterionic BCs

Poly(acrylic acid)-block-polystyrene (PAA-b-PS) BC (1; cf. Scheme 1), with degrees of polymerization of about 43 and 148 of the PAA and PS blocks, respectively, was synthesized as reported previously. ${ }^{9}$
Synthesis of poly\{N-(3-dimethylamino-1-propyl) acrylamide-ran-[ $\omega$-perfluoroalkyl poly(ethylene glycol) acrylate]\}-block-polystyrene

[P(DMAPrAAm- $r$ - $\left.\mathrm{R}_{\mathrm{f}} \mathrm{PEGA}\right)-b-\mathrm{PS}$ or 2; Scheme 1]

PAA- $b$-PS (1; 4 g or 9.3 mmol of acrylic acid) was dissolved in $12 \mathrm{~mL}$ of anhydrous pyridine in a roundbottom flask purged with dry nitrogen. In a separate flask, DIC (0.438 g, $3.47 \mathrm{mmol})$, DMAP (0.170 g, 1.39 $\mathrm{mmol})$, and Zonyl FSO-100 (1.675 g, $2.3 \mathrm{mmol})$ were dissolved in $8 \mathrm{~mL}$ of anhydrous pyridine, and this solution was added dropwise to the flask containing PAA- $b$-PS. After the reaction mixture was stirred for $48 \mathrm{~h}$ at $40^{\circ} \mathrm{C}$, a solution containing DIC (2.322 g, $18.4 \mathrm{mmol})$, DMAP $(0.566 \mathrm{~g}, 4.63 \mathrm{mmol})$, and 3-(dimethylamino)-1-propylamine (4.73 g, $46.3 \mathrm{mmol})$ was added dropwise to the polymer solution in the reaction flask, and the mixture was stirred at $40^{\circ} \mathrm{C}$ for an additional $48 \mathrm{~h}$. After the mixture cooled to room temperature, the $\mathrm{BC}$ was recovered by precipitation in hexane and dried in vacuo at $50^{\circ} \mathrm{C}$ for about $12 \mathrm{~h}$.

Yield: $5.48 \mathrm{~g}$ (ca. 94\%). ${ }^{1} \mathrm{H}-\mathrm{NMR}\left(400 \mathrm{MHz}, \mathrm{CDCl}_{3}\right.$,

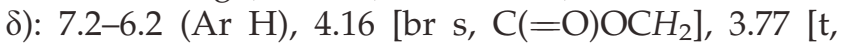
$\mathrm{C}(=\mathrm{O}) \mathrm{OCH}_{2} \mathrm{CH}_{2}$ ], 3.64 (br s, $\mathrm{OCH}_{2} \mathrm{CH}_{2} \mathrm{O}$ ), 3.2 [br d, $\left.\mathrm{C}(=\mathrm{O}) \mathrm{NHCH}_{2} \mathrm{CH}_{2}\right], 2.42\left(\mathrm{~m}, \mathrm{CH}_{2} \mathrm{CF}_{2}\right), 2.36$ [br s, $\left.\mathrm{CH}_{2} \mathrm{~N}\left(\mathrm{CH}_{3}\right)_{2}\right], 2.2$ [br s, $\left.\mathrm{N}\left(\mathrm{CH}_{3}\right)_{2}\right], 1.6$ [br s, $\mathrm{CH}_{2} \mathrm{CH}_{2} \mathrm{~N}\left(\mathrm{CH}_{3}\right)_{2}$ ], 2-1 $\left(\mathrm{CH}_{2}, \mathrm{CH}\right.$, backbone). IR (dry 
film, $\left.v_{\max }, \mathrm{cm}^{-1}\right): 3201,3082,3060,3026,3002,2928$, 2855, 2782, 1732, 1636, 1617, 1602, 1567, 1493, 1452, $1368,1348,1303,1240,1218,1178,1151,1107,1029$, 908, 756, 699, 540 .

Synthesis of poly $\{N$-(3-acrylamidopropyl)- $N, N-$ dimethylammonioacetate-ran-[ $\omega$-perfluoroalkyl poly (ethylene glycol) acrylate]\}-block-polystyrene [P(AAmPrDMAAc- $\left.r-R_{\mathrm{f}} \mathrm{PEGA}\right)-b$-PS or 3; Scheme 1]

The BC P(DMAPrAAm- $r-R_{\mathrm{f}}$ PEGA)- $b$-PS (0.5 g or $0.67 \mathrm{mmol}$ of DMAPrAAm) was dissolved in dry DMF (2 mL). To this solution, a solution of bromoacetic acid $(0.3848 \mathrm{~g}, 2.77 \mathrm{mmol})$ in acetonitrile (1 $\mathrm{mL}$ ) was added slowly. After the mixture was stirred at $80^{\circ} \mathrm{C}$ for $48 \mathrm{~h}$, it was cooled to room temperature, and a solution of $\mathrm{KOH}(0.1602 \mathrm{~g}, 2.857$ $\mathrm{mmol})$ in methanol $(0.5 \mathrm{~mL})$ was added. The mixture was further stirred for $30 \mathrm{~min}$ at room temperature. The quaternized $\mathrm{BC}$ was precipitated in cold $\mathrm{Et}_{2} \mathrm{O}$, filtered, washed with $\mathrm{Et}_{2} \mathrm{O}$, dried, washed again with distilled water, and finally, dried to a constant mass in a vacuum oven at about $50^{\circ} \mathrm{C}$.

Yield: $0.48 \mathrm{~g}$ (ca. 89\%). IR (dry film, $v_{\max }, \mathrm{cm}^{-1}$ ): 3260, 3083, 3061, 3026, 2927, 2855, 1743, 1615, 1493, 1452, 1399, 1243, 1204, 1106, 1029, 908, 757, 699, 538.

Synthesis of poly\{[N-(3-acrylamidopropyl)-N,N-

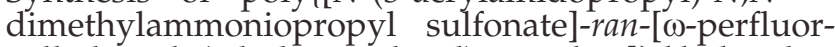
oalkyl poly(ethylene glycol) acrylate]\}-block-polystyrene [P(AAmPrDMAPS- $\left.r-R_{\mathrm{f}} \mathrm{PEGA}\right)-b-\mathrm{PS}$ or 4 ; Scheme 1]

The BC P(DMAPrAAm- $r-R_{\mathrm{f}}$ PEGA)- $b$-PS (1 g or 1.35 mmol of DMAPrAAm) was dissolved in dry DMF (4 $\mathrm{mL})$. A solution of 1,3-propanesultone (0.677 g, 5.54 $\mathrm{mmol})$ in DMF (2 $\mathrm{mL})$ was added dropwise to the polymer solution. After the mixture was stirred at $80^{\circ} \mathrm{C}$ for $48 \mathrm{~h}$, it was cooled to room temperature and poured into an excess of acetone. The precipitated polymer was filtered, washed with acetone, and dried in vacuo at $50^{\circ} \mathrm{C}$.

Yield: $1.09 \mathrm{~g}$ (ca. 94\%). IR (dry film, $v_{\max }, \mathrm{cm}^{-1}$ ): 3275, 3082, 3060, 3026, 3003, 2928, 2856, 1731, 1624, 1493, 1452, 1366, 1350, 1207, 1187, 1038, 908, 757, 699, $666,607,538$.

Synthesis of poly\{[N-(3-acrylamidopropyl)-N,Ndimethyl-N-(carbomethoxymethyl)ammonium bromide]-ran-[ $\omega$-perfluoroalkyl poly(ethylene glycol) acrylate]\}-block-polystyrene [P(AAmPrDMABr-r$\left.\mathrm{R}_{\mathrm{f}} \mathrm{PEGA}\right)-b$-PS or 5; Scheme 1]

The BC P(DMAPrAAm- $r$-R $\mathrm{f}$ PEGA)- $b$-PS (1 g or 1.35 mmol of DMAPrAAm) was dissolved in dry DMF (4 $\mathrm{mL})$. Methyl bromoacetate $(0.8475 \mathrm{~g}, 5.54 \mathrm{mmol})$ was dissolved in $2 \mathrm{~mL}$ of DMF, and the solution was added dropwise to the flask containing the polymer. The reaction mixture was stirred at $80^{\circ} \mathrm{C}$ for $48 \mathrm{~h}$. The solution was then cooled to room temperature, and the polymer was precipitated into an excess of acetone. After filtration, the polymer was dried in vacuo at $50^{\circ} \mathrm{C}$.

Yield: $1.08 \mathrm{~g}$ (ca. 91\%). IR (dry film, $v_{\max }, \mathrm{cm}^{-1}$ ): 3082, 3060, 3026, 3002, 2925, 2853, 1743, 1709, 1601, $1493,1452,1384,1350,1238,1218,1153,1117,1029$, $907,845,758,699,568,540$.

Synthesis of the homopolymer poly[N-(3-dimethylamino-1-propyl)acrylamide] [P(DMAPrAAm]

N-(3-Dimethylamino-1-propyl)acrylamide (6 g, 38.4 mmol) was mixed with $98.5 \mathrm{mg}(0.6 \mathrm{mmol})$ of AIBN and $3 \mathrm{~mL}$ of dry toluene in a $25-\mathrm{mL}$, round-bottom flask. The flask was deoxygenated by purging with nitrogen. Polymerization was carried out at $70^{\circ} \mathrm{C}$ for $20 \mathrm{~h}$. After the solution cooled to room temperature, the polymer was precipitated in an excess of cold hexanes, filtered, and dried in a vacuum oven at $50^{\circ} \mathrm{C}$.

Yield: $5.32 \mathrm{~g}$ (ca. 89\%). IR (KBr, dry film, $v_{\max }$ $\mathrm{cm}^{-1}$ ): 3292, 3076, 2944, 2862, 2817, 2778, 1647, 1548, 1463, 1376, 1262, 1237, 1182, 1159, 1100, 1041, 972, $844,753,664$.

Synthesis of the homopolymer poly[N-(3acrylamidopropyl)- $N, N$-dimethylammonioacetate] [P(AAmPrDMAAc $)]$

Poly[N-(3-dimethylaminopropyl)acrylamide]

[P(DMAPrAAm); $1 \mathrm{~g}$ or $6.4 \mathrm{mmol}$ of DMAPrAAm] was placed in a round-bottom flask and was dissolved in dry DMF (8 mL). 2-Bromoacetic acid (3.92 $\mathrm{g}, 28.2 \mathrm{mmol})$, dissolved in DMF $(2 \mathrm{~mL})$, was added dropwise to the polymer solution. Subsequent to a reaction at $80^{\circ} \mathrm{C}$ for $24 \mathrm{~h}$, the mixture was cooled to room temperature, and the polymer was precipitated in excess acetone, filtered, and washed further with acetone. After it was dried in a vacuum oven at room temperature, the polymer was redissolved in a $1: 1 \mathrm{v} / \mathrm{v}$ water/methanol mixture $(3 \% \mathrm{w} / \mathrm{v}$ concentrated polymer). The solution was passed through a column packed with an ion-exchange resin to remove bromide anions. The polymer was recovered from the eluent by distillation of the solvent with a rotary evaporator and drying in vacuo at $50^{\circ} \mathrm{C}$ (yield: $1.2 \mathrm{~g}$, са. $90 \%$ ).

Synthesis of the homopolymer poly $[N-(3-$ acrylamidopropyl)- $N, N$-dimethylammoniopropyl sulfonate $)][\mathrm{P}(\mathrm{AAmPrDMAPS})]$

P(DMAPrAAm) (1 g or $6.4 \mathrm{mmol}$ of DMAPrAAm) was placed in a round-bottom flask and dissolved in dry DMF (8 mL). Then, $1.56 \mathrm{~g}$ (12.8 mmol) of 1,3propanesultone dissolved in DMF $(2 \mathrm{~mL})$, was added slowly to the polymer. The reaction mixture was stirred at $80^{\circ} \mathrm{C}$ for $24 \mathrm{~h}$. The solution was cooled to room temperature, and the polymer was 


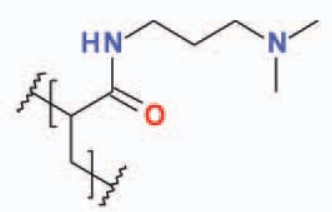

$N$-(3-dimethylamino-1-propyl)acrylamide (DMAPrAAm)

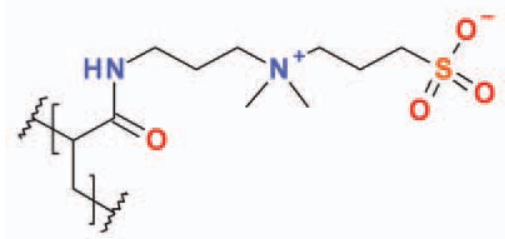

$N$-(3-acrylamidopropyl)- $N, N$-dimethylammonio propylsulfonate (AAmPrDMAPS)

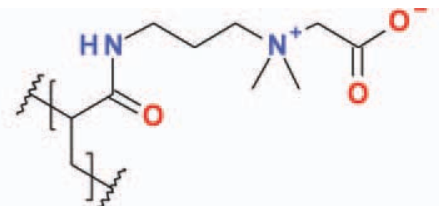

$N$-(3-acrylamidopropyl)- $N, N$-dimethylammonioacetate (AAmPrDMAAc)

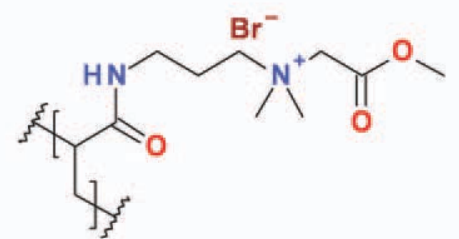

$N$-(3-acrylamidopropyl)- $N, N$-dimethyl- $N$-(carbomethoxymethyl) ammonium bromide (AAmPrDMABr)

Figure 1 Chemical structures of the acrylamide precursor and its zwitterionic and cationic derivatives. AAmPrDMAAc is a carboxybetaine molecule, and AAmPrDMPAS is a sulfobetaine. [Color figure can be viewed in the online issue, which is available at wileyonlinelibrary.com.]

precipitated in acetone, filtered, and dried in a vacuum oven at $50^{\circ} \mathrm{C}$ (yield: $1.6 \mathrm{~g}$, ca. $90 \%$ ).

\section{Synthesis of the homopolymer PPFS}

The homopolymer of PFS was synthesized by conventional free-radical polymerization. The monomer $(5.15 \mathrm{~g}, 0.0265 \mathrm{~mol})$ was mixed with AIBN initiator $(0.0435 \mathrm{~g}, 0.265 \mathrm{mmol})$ in a $25-\mathrm{mL}$, round-bottom flask. The solution was purged with nitrogen for 20 min. The polymerization was carried out at $70^{\circ} \mathrm{C}$ for $40 \mathrm{~min}$. After cooling to room temperature, the solid in the flask was dissolved in chloroform. The polymer was recovered by precipitation in excess methanol and vacuum-dried at $50^{\circ} \mathrm{C}$ (yield: $4.12 \mathrm{~g}$, ca. $80 \%)$.

\section{RESULTS AND DISCUSSION}

\section{Molecular design of the ionic BCs}

The ionic BCs and homopolymers of this work were based on the $\mathrm{N}$-[3-(dimethylamino)propyl]acrylamide monomer. Figure 1 shows the chemical structures of this monomer and its ionic derivatives.

Each BC consisted of a PS block and an ionic block and was synthesized by atom transfer radical polymerization (ATRP) and polymer analogous reactions. Ionic mers, which are significantly more polar than PS, would normally be buried below the PS block when the coatings are processed in air. ${ }^{12,38}$ However, following the approaches of Thanawala and Chaudhury ${ }^{39}$ and Koberstein, ${ }^{40}$ who showed that a high-energy group can be pulled to the airpolymer interface by the driving forces of the lower surface energy groups segregating to the surface, we introduced a small number of low-surface-energy mers, consisting of $\mathrm{R}_{\mathrm{f}} \mathrm{PEG}$ side groups (cf. Fig. 2) in the ionic block. Our previous studies showed that in BC coatings prepared with this monomer, the lowsurface-energy fluoroalkyl groups anchored the polymer chain at the air-polymer interface, and the hydrophilic PEG segment retained the polymer chain at the surface in aqueous environments., 10,41

\section{Zwitterionic and cationic BC synthesis}

The general techniques for the synthesis of zwitterionic polymers have been reviewed by Kudaibergenov et al. ${ }^{42}$ We used the approach of polymer analogous reactions to prepare the zwitterionic and cationic BCs, which also contained the surfacedirecting $\mathrm{R}_{\mathrm{f}} \mathrm{PEG}$ side groups (Scheme 1). PAA-blockPS BC was synthesized with ATRP of tert-butyl acrylate and styrene followed by the conversion of the tert-butyl ester to carboxylic acid by hydrolysis. ${ }^{9}$ The degree of polymerization of the acrylic acid block

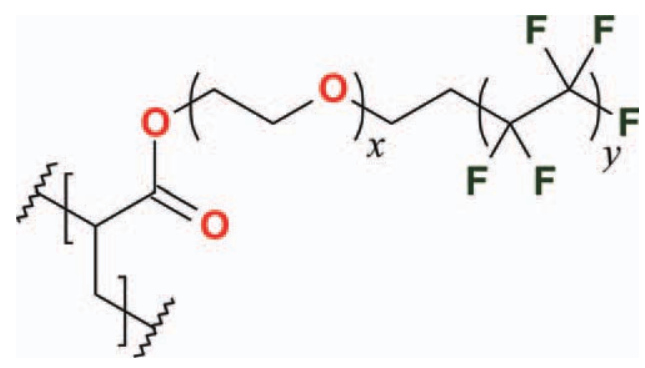

Figure 2 Chemical structure of the $\mathrm{R}_{\mathrm{f}} \mathrm{PEGA}$ surfaceanchoring group. The side chain had a relatively broad distribution of PEG and fluoroalkyl chain lengths. The average values of $x$ and $y$ are about $5.5 \pm 0.5$ and $3.5 \pm 0.5$, respectively. [Color figure can be viewed in the online issue, which is available at wileyonlinelibrary.com.] 
was about 43 , and that of the PS block was 148 . The molecular weight distribution of the original poly(tert-butyl acrylate)-block-PS, determined by gel permeation chromatography, was narrow (polydispersity index $=1.09$ ). Partial esterification of the acrylic acid mers with the hydroxyl groups of the $\mathrm{R}_{\mathrm{f}} \mathrm{PEG}$ surfactant, Zonyl FSO-100, was preceded by the activation of about $37.5 \%$ of the carboxylic acid groups with DIC, followed by reaction with the alcohol (ca. $25 \mathrm{~mol} \%$ of the carboxylic acid groups). At the end of the first step, the remaining carboxylic acid groups of the PAA block were reacted with an excess $(5 \times)$ of 3-(dimethylamino)-1-propylamine with the DIC/DMAP mediated amide formation. The reaction mixture gelled when the amine was added (because of hydrogen-bonding interactions of the amino and carboxylic acid groups), but as the amide formation reaction progressed, a gradual decrease in the viscosity was observed. At the end of the reaction, a completely soluble functionalized polymer was obtained. The esterification and amide formation reactions were monitored with ${ }^{1} \mathrm{H}-\mathrm{NMR}$ spectroscopy. The extent of attachment of $\mathrm{R}_{\mathrm{f}} \mathrm{PEG}$ was determined using the peak at $4.16 \mathrm{ppm}$, which arises from the two $-\mathrm{C}(=\mathrm{O}) \mathrm{OCH}_{2}-$ protons, to be $17.3 \%$. In other words, of the $43-\mathrm{COOH}$ groups in the PAA block, an average of 7.4 groups had reacted with $\mathrm{R}_{\mathrm{f}} \mathrm{PEG}$. Because an excess of 3-(dimethylamino)-1-propylamine was used in the second step of the reaction, almost all of the remaining $-\mathrm{COOH}$ groups were converted to the corresponding amide. Except for product loss during workup, the reaction yield was almost quantitative.

The procedures used for the quaternization reactions were similar to those reported in the literature for quaternization of tertiary amines with bromoacetic acid $^{43}$ and 1,3-propanesultone. ${ }^{44}$ The precursor BC was also reacted with methyl 2-bromoacetate. FTIR spectroscopy was used to monitor the quaternization reactions. On the basis of the IR spectrum of the P(DMAPrAAm) homopolymer (cf. Infrared Spectroscopy section), the peak at $2778 \mathrm{~cm}^{-1}$ in the IR spectrum of P(DMAPrAAm- $\left.r-\mathrm{R}_{\mathrm{f}} \mathrm{PEGA}\right)-b$-PS (2) was attributed to $>\mathrm{N}\left(\mathrm{CH}_{3}\right)_{2} \mathrm{C}-\mathrm{H}$ stretching vibrations. ${ }^{45}$ After reactions with bromoacetic acid, 1,3-propanesultone, and methyl-2-bromoacetate, this peak disappeared; this indicated that the tertiary amine groups had undergone the quaternization reaction. All of the ionic polymers of this study were completely soluble in polar solvents such as DMF, despite the high extent of the quaternization reaction.

The design strategy used herein was different from that of Sundaram et al., ${ }^{46}$ who recently reported the marine antibiofouling properties of surface-active zwitterionic BCs. These polymers were prepared with poly(dimethylaminoethyl methacrylate)-block-PS precursors synthesized by ATRP. The

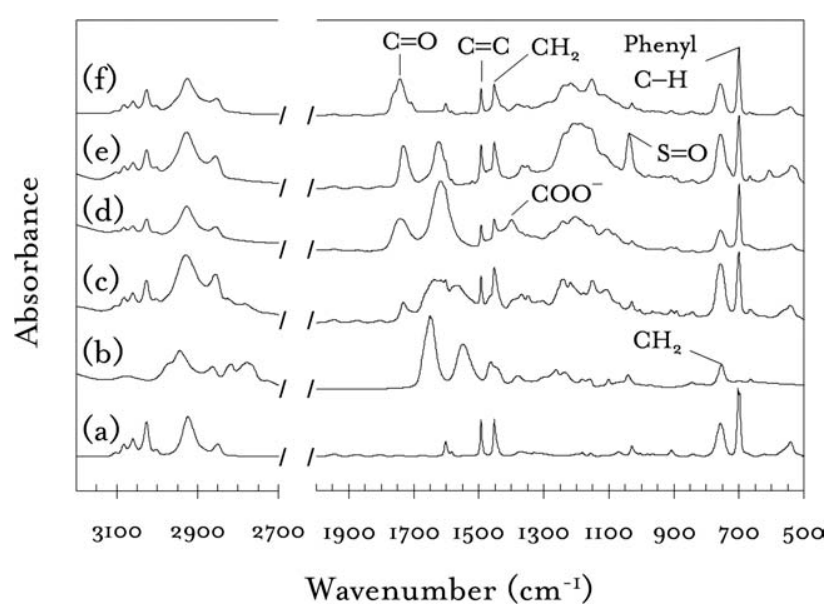

Figure 3 FTIR spectra of (a) PS, (b) P(DMAPrAAm), (c) P(DMAPrAAm- $r-R_{\mathrm{f}}$ PEGA)- $b$-PS (2), (d) P(AAmPrDMAAc-

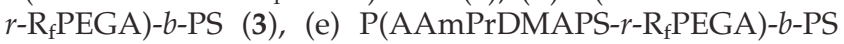
(4), and (f) $\mathrm{P}\left(\mathrm{AAmPrDMABr}-r-\mathrm{R}_{\mathrm{f}} \mathrm{PEGA}\right)-b$-PS (5).

dimethylaminoethyl groups were reacted with an $\left(\mathrm{R}_{\mathrm{f}} \mathrm{PEG}\right)$ 2-oxodioxaphospholane derivative to introduce phosphobetaine zwitterions into the polymer side chains. The 2-oxodioxaphospholane derivative performed the dual roles of a quaternization agent and a surface-directing group. In the BCs of this study, however, the surface-directing $\mathrm{R}_{\mathrm{f}} \mathrm{PEG}$ mers and the ionic mers were separate, and their relative numbers could be independently controlled (cf. Scheme 1). Only a small number of the $R_{f} P E G$ groups $(17.3 \mathrm{~mol} \%)$ were incorporated into the surface-active block so that a large fraction of the surface sites were occupied by the ionic mers (instead of the PEG or fluoroalkyl moieties).

In contrast to polymers with dimethylaminoethyl side chains, which have been widely studied in the past, the additional methylene group in the propyl spacer (that connects the ionic group to the polymer backbone) of this study was expected favor surface segregation of the ionic side chains. Liaw et al. ${ }^{47}$ used propiolactone to synthesize polycarboxybetaines, wherein the ammonium and carboxylate ions were separated by three methylene groups. However, the use of 2-bromoacetic acid, as in this work, results in only one methylene group between the cation and the anion, which affects the intercharge length, the dipole moment, and the hydration characteristics of the zwitterion.

\section{Infrared spectroscopy}

Figure 3 shows the IR spectra of the three ionic copolymers, the P(DMAPrAAm- $r-R_{f}$ PEGA)- $b$-PS BC precursor, the P(DMAPrAAm) homopolymer, and PS.

The peak corresponding to amide $\mathrm{C}=\mathrm{O}$ stretching vibrations occurred at $1647 \mathrm{~cm}^{-1}$ in P(DMAPrAAm). The ester $\mathrm{C}=\mathrm{O}$ stretching vibrations were observed 
at about $1732 \mathrm{~cm}^{-1}$ for P(DMAPrAAm- $r$-R $\left.\mathrm{R}_{\mathrm{f}} \mathrm{PEGA}\right)-b$ PS and P(AAmPrDMAPS- $r$ - $\left.\mathrm{R}_{\mathrm{f}} \mathrm{PEGA}\right)-b$-PS and at $1743 \mathrm{~cm}^{-1}$ for P(AAmPrDMAAc- $\left.r-R_{\mathrm{f}} \mathrm{PEGA}\right)-b$-PS and $\mathrm{P}\left(\mathrm{AAmPrDMABr}-r-\mathrm{R}_{\mathrm{f}} \mathrm{PEGA}\right)-b$-PS. The peak at $1399 \mathrm{~cm}^{-1}$ in the spectrum of $\mathrm{P}(\mathrm{AAmPrDMAAc}-r-$ $\mathrm{R}_{\mathrm{f}} \mathrm{PEGA}$ )- $b$-PS (3) was attributed to the $\mathrm{COO}^{-}$symmetric stretching vibrations. The peak at $1038 \mathrm{~cm}^{-1}$ in the spectrum of $\mathrm{P}\left(\mathrm{AAmPrDMAPS}-r-\mathrm{R}_{\mathrm{f}} \mathrm{PEGA}\right)-b$-PS (4) was due to the $S=O$ stretching vibrations. The peak near $757 \mathrm{~cm}^{-1}$ was attributed to the $\mathrm{CH}_{2}$ rocking vibration (in the polymer backbone and side chains), and that at $1452 \mathrm{~cm}^{-1}$ was due to $\mathrm{CH}_{2}$ scissor vibrations. The peak at $699 \mathrm{~cm}^{-1}$ was due to the out-of-plane bending vibrations of the five hydrogen atoms attached to the PS phenyl ring, and that at $1493 \mathrm{~cm}^{-1}$ was attributed to aryl $\mathrm{C}=\mathrm{C}$ stretching vibrations. From the IR spectrum of polytetrafluoroethylene, asymmetric and symmetric $\mathrm{CF}_{2}$ stretching was expected at 1241 and $1208 \mathrm{~cm}^{-1}$. The peak at $1106 \mathrm{~cm}^{-1}$ was attributed to the $\mathrm{C}-\mathrm{O}$ stretching vibrations of the $-\mathrm{CH}_{2} \mathrm{CH}_{2} \mathrm{O}-$ segments (cf. Fig. 2).

\section{XPS}

Figure 4 shows the $C$ 1s XPS spectra of the surfaces of the BCs P(AAmPrDMAPS- $r$ - $\left.\mathrm{R}_{\mathrm{f}} \mathrm{PEGA}\right)-b$-PS and $\mathrm{P}\left(\mathrm{AAmPrDMABr}-r-\mathrm{R}_{\mathrm{f}} \mathrm{PEGA}\right)-b$-PS. The BCs were spin-coated on silicon wafers, and the films were annealed in a vacuum oven at $120^{\circ} \mathrm{C}$ for about $12 \mathrm{~h}$. These spectra were acquired at $\phi=70^{\circ}$. The spectra were resolved into subpeaks with a series of Gaussian-Lorentzian curves and a Tougaard background.

In XPS, about $63.2 \%$ of the experimentally determined XPS peak intensities is attributable to photoelectrons emitted from the topmost layer of film, with a thickness of $\lambda \cos \phi$, where $\lambda$ is the inelastic mean free path of the electrons. ${ }^{48}$ A second layer, with a thickness of $\lambda \cos \phi$, results in an additional $23.3 \%$ of the detected photoelectrons. A third layer of the same thickness makes a contribution of only about $8.5 \%$ to the detected peak intensity. Hence, for the spectra reported in Figure 4, the probe depth was approximately $2 \mathrm{~nm}(\approx 2 \lambda \cos \phi)$, where $\lambda$ of the photoelectrons was estimated ${ }^{9}$ to be about $3 \mathrm{~nm}$ for the BCs). About $86.5 \%$ of the XPS signal resulted from atoms located within this depth.

Peaks 1 and 2 were attributed to the $-\mathrm{CF}_{3}$ and $-\mathrm{CF}_{2}-$ carbon atoms, respectively. The $\pi \rightarrow \pi^{*}$ shakeup satellite peak of the PS phenyl rings was also expected in this region $(290-294 \mathrm{eV})$. From the fraction areas of peaks 1 and 2, it was inferred that less than $15 \%$ of the carbon atoms in the top $2 \mathrm{~nm}$ of the film were fluorinated. Peaks 3 and 4 were attributed to the $\mathrm{C}=\mathrm{O}$ carbon atoms of the ester and amide groups in the polymers. The cationic BC 5 contained additional $-\mathrm{C}(=\mathrm{O}) \mathrm{OCH}_{3}$ ester groups in the side chains. Peak 5 was attributed to carbon atoms
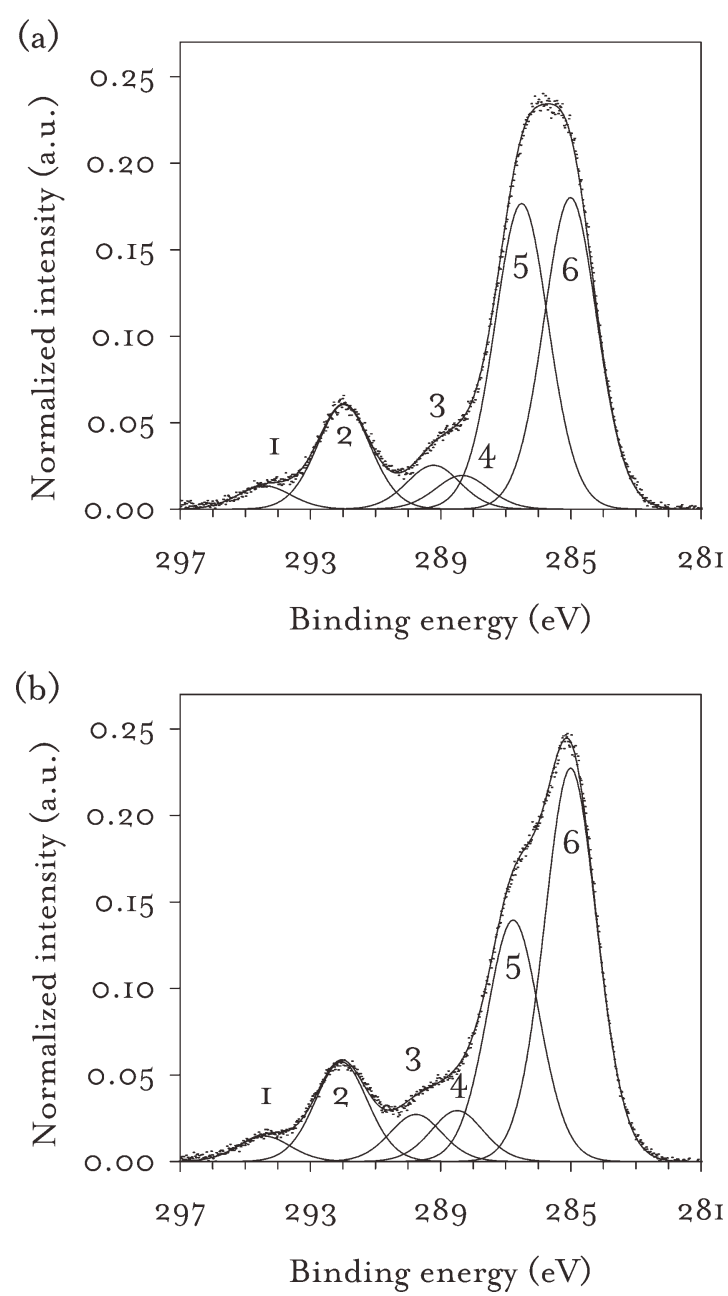

Figure 4 High-resolution C1s XPS spectra of BCs: (a) P(AAmPrDMAPS- $r$ - $R_{\mathrm{f}}$ PEGA)- $b$-PS (4) and (b) P(AAmPrDMABr- $r$-R $\mathrm{f}$ PEGA)- $b$-PS (5).

attached to the heteroatoms $\mathrm{O}, \mathrm{S}$, and $\mathrm{N}$ in the $\mathrm{BCs}$. Hence, the surfaces of the $\mathrm{BC}$ films contained a large number of ionic mers; this was also evident from the contact angle studies reported in the following section. Peak 6 was attributed to $\mathrm{C}-\mathrm{C}$ carbon atoms in the $B C$ and to the $C=C$ carbon atoms of the PS mers, which constituted about $78 \mathrm{~mol} \%$ of the BC. Despite the large mole fraction of styrene and the lower surface energy of styrene compared to the ionic mers (cf. the Surface Wettability and Surface Energy section), the presence of the ionic block at the surface was attributed to the relatively low-surface-energy $\mathrm{R}_{\mathrm{f}} \mathrm{PEG}$ surface anchoring groups (Fig. 2). The surface concentration of ionic mers would be even higher when the coatings are immersed in an aqueous environment. The composition depth profiles in the ionic BC thin films were investigated in detail and will be reported separately.

The carboxybetaine polymers were obtained by the reaction of DMAPrAAm mers with bromoacetic acid. The bromide ions in the $\mathrm{BC}$ were removed by reaction with $\mathrm{KOH}$ (cf. Scheme 1). The excess $\mathrm{KOH}$ 
TABLE I

$\theta_{a}$ and $\theta_{r}\left({ }^{\circ}\right)$ Values of Different Probe Liquids ${ }^{a}$ on the Surfaces of the Polymer Thin Films

\begin{tabular}{|c|c|c|c|c|c|c|c|c|c|c|c|}
\hline & \multicolumn{2}{|c|}{ WA } & \multicolumn{2}{|c|}{ EG } & \multicolumn{2}{|c|}{ HD } & \multicolumn{2}{|c|}{ DIM } & \multicolumn{2}{|c|}{$\mathrm{BN}$} & \multirow{2}{*}{$\frac{\mathrm{GL}}{\theta_{a}}$} \\
\hline & $\theta_{a}$ & $\theta_{r}$ & $\theta_{a}$ & $\theta_{r}$ & $\theta_{a}$ & $\theta_{r}$ & $\theta_{a}$ & $\theta_{r}$ & $\theta_{a}$ & $\theta_{r}$ & \\
\hline 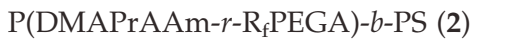 & 73 & 21 & 69 & 20 & 48 & 43 & 72 & 25 & 52 & 43 & 90 \\
\hline $\mathrm{P}\left(\mathrm{AAmPrDMAAc}-r-\mathrm{R}_{\mathrm{f}} \mathrm{PEGA}\right)-b$-PS (3) & 64 & 14 & 58 & 14 & 47 & 16 & 80 & 11 & 60 & 11 & 86 \\
\hline $\mathrm{P}\left(\mathrm{AAmPrDMAPS}-r-\mathrm{R}_{\mathrm{f}} \mathrm{PEGA}\right)-b$-PS (4) & 66 & 14 & 62 & 12 & 44 & 36 & 69 & 22 & 61 & 12 & 80 \\
\hline $\mathrm{P}\left(\mathrm{AAmPrDMABr}-r-\mathrm{R}_{\mathrm{f}} \mathrm{PEGA}\right)-b-\mathrm{PS}(5)$ & 70 & 18 & 74 & 30 & 40 & 28 & 75 & 45 & 75 & 45 & 91 \\
\hline P(AAmPrDMAAc) & $\approx 0$ & $\approx 0$ & 21 & 12 & 37 & 21 & 66 & 57 & 56 & 48 & 45 \\
\hline P(AAmPrDMAPS) ${ }^{\mathrm{b}}$ & $\approx 0$ & $\approx 0$ & 26 & 12 & 27 & 21 & 51 & 25 & 44 & 27 & 28 \\
\hline PS & 97 & 83 & 62 & 55 & 11 & $\approx 0$ & 11 & $\approx 0$ & 15 & 11 & 74 \\
\hline PPFS & 107 & 85 & 72 & 53 & 30 & 17 & 64 & 15 & 52 & 34 & 95 \\
\hline
\end{tabular}

${ }^{\text {a } W A}$, water; EG, ethylene glycol; HD, hexadecane; DIM, diiodomethane; GL, glycerol; BN, $\alpha$-bromonaphthalene.

${ }^{\mathrm{b}} \theta_{a}$ of dimethyl sulfoxide on $\mathrm{P}(\mathrm{AAmPrDMAPS})$ was $12^{\circ}$.

and $\mathrm{KBr}$ were then removed by extraction in water. The absence of $\mathrm{Br} 3 \mathrm{~d}$ peaks (expected near a binding energy of $70 \mathrm{eV})$ or the $\mathrm{K} 2 \mathrm{p}(294 \mathrm{eV})$ and $\mathrm{K} 2 \mathrm{~s}(377$ $\mathrm{eV}$ ) peaks in XPS survey scans (data not shown) indicated that there were no residual bromide or potassium ions in the carboxybetaine polymers.

\section{Surface wettability and surface energy}

Thin films of the polymers were prepared by spincoating solutions of the polymers in suitable solvents on glass substrates. The nonionic precursor $B C$, P(DMAPrAAm- $r$ - $\left.\mathrm{R}_{\mathrm{f}} \mathrm{PEGA}\right)-b$-PS, and the cationic BC, $\mathrm{P}\left(\mathrm{AAmPrDMABr}-r-\mathrm{R}_{\mathrm{f}} \mathrm{PEGA}\right)-b$-PS, were spin-coated with $3 \%(\mathrm{w} / \mathrm{v})$ solutions in chloroform. The zwitterionic BCs were spin-coated with $3 \%(\mathrm{w} / \mathrm{v})$ solutions in a DMF-methanol blend $(8: 1 \mathrm{v} / \mathrm{v})$. The zwitterionic homopolymers were spin-coated with $3 \%$ $(\mathrm{w} / \mathrm{v})$ solutions in distilled water. Thin films of PS and PPFS were also prepared (from $3 \% \mathrm{w} / \mathrm{v}$ solutions in chloroform) and used as references for the surface wettability studies. Because PPFS is a fluorinated polymer, it was expected to have a lower surface energy than PS. After spin coating, the films were dried at $60^{\circ} \mathrm{C}$ for $24 \mathrm{~h}$ and further annealed at $120^{\circ} \mathrm{C}$ in a vacuum oven for $24 \mathrm{~h}$.

The sessile drop method was used to determine the advancing contact angle $\left(\theta_{a}\right)$ and receding contact angle $\left(\theta_{r}\right)$ values of several probe liquids on the spin-coated BC surfaces. Table I gives the contact angles measured in air at room temperature.

All of the contact angles reported in Table I are averages of at least three measurements. The measurement uncertainty was less than $2^{\circ}$ for contact angles greater than about $30^{\circ}$ (except in the case of glycerol, for which the uncertainty was about $4^{\circ}$ because of its high viscosity). For lower contact angles, the measurement uncertainty was about $4^{\circ}$. The $\theta_{r}$ values of glycerol could not be determined.

The BC surfaces were hydrophilic, with advancing and receding water contact angles $\left(\theta_{a, w}\right.$ and $\theta_{r, w}$, respectively) significantly below $90^{\circ}$. The contact angles were different from the values for PS. Therefore, although about $77.5 \mathrm{~mol} \%$ of the BCs were styrene mers, a significant concentration of the ionic mers was present at the surface; this was attributed to the low surface energy of fluoroalkyl poly(ethylene glycol) acrylate ( $\mathrm{R}_{\mathrm{f}} \mathrm{PEGA}$ ) surface-anchoring groups. $\theta_{a, w}$ and $\theta_{r, w}$ of the ionic BCs $\mathbf{3}, \mathbf{4}$, and $\mathbf{5}$ were significantly lower than those of the nonionic precursor BC 2 and also those of the nonionic BC $\mathrm{P}\left(\mathrm{R}_{\mathrm{f}} \mathrm{PEGA}\right)-b$-PS $\left(\theta_{a, w}=86^{\circ}\right.$ and $\left.\theta_{r, w}=41^{\circ}\right)$ reported previously; ${ }^{3}$ this indicated that the surface wettability was predominantly influenced by the ionic mers. The $\mathrm{R}_{\mathrm{f}} \mathrm{PEGA}$ mers in these copolymers only functioned as surface anchors, and their effect on water wettability was relatively small. The water contact angles on the zwitterionic BCs were slightly lower than those on the $\mathrm{BC}$ with cationic groups, evidently because of the relatively nonpolar, terminal $-\mathrm{CH}_{3}$ group in the cationic side chains.

Contact angle hysteresis (the difference between $\theta_{a}$ and $\theta_{r}$ ) is caused by factors such as chemical and topographical heterogeneity and surface reconstruction of the polymer after contact with the probe liquid. The spin-coated and thermally annealed surfaces were expected to have surface roughnesses in the nanometer range. All four BC surfaces showed large hysteresis values, mainly because of chemical heterogeneity (a combination of highly polar and nonpolar groups in the polymer microstructure) and surface reconstruction.

\section{Surface energy}

The surface energy of a solid is usually determined by the study of the contact angles of probe liquids on the solid. There are only a few reports on the surface energies of zwitterionic polymers. ${ }^{49,50}$ Hiwatashi et al. ${ }^{49}$ found that the surface energies of ionic random terpolymer films containing the carboxybetaine $N$-(2-methacryloyloxyethyl)- $N, N$-dimethylammonioacetate or the cationic mer $\mathrm{N}$-(2-methacryloyloxyethyl)- 
$\mathrm{N}, \mathrm{N}$-dimethyl-N-ethyl ammonium ethyl sulfate ranged from about 38 to $64 \mathrm{~mJ} / \mathrm{m}^{2}$ with a variation in the number of ionic mers from 35 to $60 \mathrm{~mol} \%$. The other two monomers in the terpolymers were the nonionic methyl methacrylate and iso-butyl methacrylate. The surface energies were calculated with static contact angles.

In this study, the surface energy model of Owens, Wendt, and Kaelble $(\mathrm{OWK})^{51}$ was used to estimate the surface energy $(\gamma)$ values of the BCs. The OWK model resolves surface energy into contributions from dispersion and polar forces, and the work of adhesion at the solid-liquid interface $\left(W_{\mathrm{SL}}\right)$ is assumed to be given by the following equation:

$$
W_{\mathrm{SL}}=2 \sqrt{\gamma_{S}{ }^{d} \gamma_{L}^{d}}+2 \sqrt{\gamma_{S}^{p} \gamma_{L}^{p}}
$$

where $2 \sqrt{\gamma_{S}{ }^{d} \gamma_{L}{ }^{d}}$ is the nonpolar, dispersion contribution and $2 \sqrt{\gamma_{S}^{p} \gamma_{L}^{p}}$ is the polar contribution. The superscripts $d$ and $p$ denote the dispersion and polar components, respectively, of the surface energy of the solid (denoted by subscript $S$ ) and that of the probe liquid (denoted by subscript $L$ ). $\gamma^{d}$ and $\gamma^{p}$ are the contributions from the induced dipole-induced dipole interactions (the London or dispersive interactions) and the polar interactions [the dipoleinduced dipole (Debye), dipole-dipole (Keesom), and hydrogen-bonding interactions], respectively.

The Young-Dupré equation [eq. (2)] relates the work of adhesion to the total surface energies of the solid and liquid ( $\gamma_{S}$ and $\gamma_{L}$, respectively) and the equilibrium contact angle $(\theta)$ of the liquid on the solid:

$$
W_{\mathrm{SL}}=\gamma_{S}+\gamma_{L}-\gamma_{S L}=\gamma_{L}(1+\cos \theta)
$$

Thus, from eqs. (1) and (2), we obtain

$$
\gamma_{L}(1+\cos \theta)=2 \sqrt{\gamma_{S}^{d} \gamma_{L}^{d}}+2 \sqrt{\gamma_{S}^{p} \gamma_{L}^{p}}
$$

The two unknowns, $\gamma_{s}^{d}$ and $\gamma_{s}^{p}$ in eq. (3) may be determined with at least two probe liquids with known surface energy components $\gamma_{L}^{d}$ and $\gamma_{L}^{p}$ (cf. Table II) ${ }^{52}$ We used a matrix method to solve the set of $n$ algebraic equations in $\sqrt{\gamma_{S}^{d}}$ and $\sqrt{\gamma_{S}^{p}}$ [cf. eq. (4)]:

$$
\gamma_{L, i}\left(1+\cos \theta_{i}\right) / 2=\sqrt{\gamma_{L, i}^{p}} \sqrt{\gamma_{S}^{d}}+\sqrt{\gamma_{L, i}^{p}} \sqrt{\gamma_{S}^{p}}
$$

where $i=1$ to $n$ denotes the different probe liquids. In matrix notation

$$
\mathbf{y}=\mathbf{X \beta}
$$

where $\mathbf{y}$ is a column vector of dependent variables $\left[y_{i}=\gamma_{L, i}\left(1+\cos \theta_{i}\right) / 2\right], \boldsymbol{\beta}$ is a column vector consisting of the unknowns $\sqrt{\gamma_{S}^{d}}$ and $\sqrt{\gamma_{S}^{p}}$, and $\mathbf{X}$ is an $n$
TABLE II

Surface Energy Parameters $\left(\mathrm{mJ} / \mathrm{m}^{2}\right)$ for the Probe Liquids at $20^{\circ} \mathrm{C}$

\begin{tabular}{llll}
\hline \multicolumn{1}{c}{ Liquid } & $\gamma_{L}$ & $\gamma_{L}^{d}$ & $\gamma_{L}^{p}$ \\
\hline Water & 72.8 & 21.8 & 51 \\
Glycerol & 64 & 38 & 26 \\
Ethylene glycol & 48 & 33.8 & 14.2 \\
Dimethyl sulfoxide & 44 & 36 & 8 \\
Diiodomethane & 50.8 & 49.5 & 1.3 \\
1-Bromonaphthalene & 44.4 & 44.4 & 0 \\
Hexadecane & 27.5 & 27.5 & 0 \\
\hline
\end{tabular}

$\times 2$ matrix with the elements $\sqrt{\gamma_{L, i}{ }^{p}}$ and $\sqrt{\gamma_{L, i}{ }^{p}}$ in each of the $n$ rows.

The multiple linear regression equation for the determination of $\boldsymbol{\beta}$ is

$$
\beta=\left(\mathbf{X}^{T} \mathbf{X}\right)^{-1} \mathbf{X}^{T} \mathbf{y}
$$

where $\mathbf{X}^{T}$ is the transpose of $\mathbf{X}$. Thus, one obtains $\gamma_{S}{ }^{d}$ and $\gamma_{s}{ }^{p}$ by squaring the elements of vector $\boldsymbol{\beta}$. The total surface energy of the solid is then determined using $\gamma_{S}=\gamma_{S}{ }^{d}+\gamma_{S}{ }^{p}$.

When more than two probe solvents are used, the number of degrees of freedom $(d f)$ in the multiple regression is increased to $n-2$; this allows an estimation of uncertainties in the calculated surface energy parameters. First, the estimated values of the dependent variable $\hat{\mathbf{y}}_{\mathbf{i}}$ are obtained using $\hat{\mathbf{y}}=\mathbf{X} \boldsymbol{\beta}$, where $\hat{\mathbf{y}}$ is a column vector of the estimated values of the dependent variables. The residual is calculated as a difference of $\mathbf{y}$ and $\hat{\mathbf{y}}$. The sum of all squared residuals $\left(\mathrm{SS}_{\text {res }}\right)$ is a summation of the square of each element of the vector $\mathbf{y}-\hat{\mathbf{y}}$. The mean squared error (MSE) is given by $\mathrm{SS}_{\text {res }} / d f$ (where $d f=n-p$, where $n$ is the number of probe liquids, and $p$ is the number of parameters in the model and is equal to 2). The standard errors of the dispersion and polar components $\left(s e_{d}\right.$ and $s e_{p}$, respectively) in the estimated values of $\sqrt{\gamma_{S}{ }^{d}}$ and $\sqrt{\gamma_{S}{ }^{p}}$, respectively, are the square roots of the elements along the main diagonal of the variance-covariance matrix $\left[M S E\left(\mathbf{X}^{T} \mathbf{X}\right)^{-1}\right]$.

For the acrylamido polymers, the $\theta_{r}$ values were significantly lower than the $\theta_{a}$ values for all of the probe liquids (cf. Table I). When the $\theta_{a}$ and $\theta_{r}$ differ significantly, a question arises as to which of these angles should be used in eq. (3) to calculate the polymer surface energies. The equilibrium contact angles upon which eq. (3) is based are usually difficult to determine. The $\theta_{a}$ values are commonly used for surface energy calculations, but Della-Volpe and Siboni recommended the use of an average contact angle $(\bar{\theta})$, given by $\cos \bar{\theta}=\left(\cos \theta_{a}+\cos \theta_{r}\right) / 2 .{ }^{53}$

The surface energy values were estimated with all three angles, $\theta_{a}, \theta_{r}$, and $\bar{\theta}$, and are shown in Table III. The surface energies of the zwitterionic homopolymers $\mathrm{P}(\mathrm{AAmPrDMAAc})$ and $\mathrm{P}(\mathrm{AAmPrDMAPS})$ 
TABLE III

Surface Energies $\left(\mathrm{mJ} / \mathrm{m}^{2}\right)$ of the Polymers as Calculated with the OWK Model ${ }^{\mathrm{a}}$

\begin{tabular}{|c|c|c|c|c|c|c|c|c|c|}
\hline \multirow[b]{2}{*}{ Polymer } & \multicolumn{3}{|c|}{$\gamma_{S}{ }^{d}$} & \multicolumn{3}{|c|}{$\gamma_{s}^{p}$} & \multicolumn{3}{|c|}{$\gamma_{S}$} \\
\hline & With $\theta_{a}$ & With $\theta_{r}$ & With $\bar{\theta}$ & With $\theta_{a}$ & With $\theta_{r}$ & With $\bar{\theta}$ & With $\theta_{a}$ & With $\theta_{r}$ & With $\bar{\theta}$ \\
\hline $\begin{array}{l}\text { P(DMAPrAAm- } r- \\
\text { R }_{\mathrm{f}} \text { PEGA)- } b-\mathrm{PS}(2)\end{array}$ & $19.6(5.5)$ & $28.5(5.7)$ & $24.2(4.6)$ & $6.8(4.9)$ & $35.4(10.3)$ & $20.9(7.0)$ & $26.3(7.3)$ & $63.9(11.8)$ & $45.1(8.3)$ \\
\hline $\begin{array}{c}\text { P(AAmPrDMAAc- } r- \\
\text { R }_{\mathrm{f}} \text { PEGA)- } b \text {-PS (3) }\end{array}$ & $16.8(5.2)$ & $34.6(7.1)$ & $25.4(4.6)$ & $12.9(7.0)$ & $31.9(11.1)$ & $24.5(7.4)$ & $29.7(8.8)$ & $66.5(13.2)$ & $49.9(8.8)$ \\
\hline 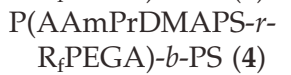 & $19.0(4.2)$ & $32.7(7.1)$ & $25.7(4.9)$ & $11.7(5.1)$ & $33.6(11.8)$ & $23.5(7.6)$ & $30.7(6.6)$ & $66.2(13.7)$ & $49.3(9.0)$ \\
\hline $\begin{array}{l}\text { P(AAmPrDMABr- } r- \\
\text { RefEA }_{\mathrm{f}} \text { - } b \text {-PS (5) }\end{array}$ & $15.3(4.8)$ & $26.0(5.2)$ & $20.8(4.1)$ & $9.9(5.9)$ & $36.7(10.1)$ & $23.7(7.2)$ & $25.2(7.6)$ & $62.7(11.4)$ & $44.5(8.3)$ \\
\hline P(AAmPrDMAAc) & $19.4(4.4)$ & $23.9(4.4)$ & $21.8(4.3)$ & $41.6(9.8)$ & $42.7(9.5)$ & $44.6(10.0)$ & $61.0(10.7)$ & $66.5(10.5)$ & $66.4(10.9)$ \\
\hline P(AAmPrDMAPS) & $23.9(4.2)$ & $31.8(6.3)$ & $28.3(5.6)$ & $38.5(8.4)$ & $35.7(10.8)$ & $38.0(10.6)$ & $62.4(9.4)$ & $67.5(12.5)$ & $66.3(12.0)$ \\
\hline PS & $40.6(5.1)$ & $39.8(6.0)$ & $40.1(5.9)$ & $0.1(0.3)$ & $1.9(2.1)$ & $0.7(1.2)$ & $40.7(5.1)$ & $41.8(6.3)$ & $40.8(6.0)$ \\
\hline PPFS & $26.6(1.9)$ & $37.0(5.1)$ & $31.8(2.6)$ & 0 & $2.2(2.1)$ & $0.8(0.7)$ & $26.6(1.9)$ & $39.2(5.5)$ & $32.5(2.8)$ \\
\hline
\end{tabular}

a $\bar{\theta}$, average angle calculated with $\cos \bar{\theta}=\left(\cos \theta_{a}+\cos \theta_{r}\right) / 2$. The uncertainties are given in parentheses.

and the nonionic polymers PS and PPFS were also determined for comparison. In Table III, the best estimates for $\gamma_{S}{ }^{d}, \gamma_{S}{ }^{p}$, and $\gamma_{S}$ are shown with the uncertainties in these values. The uncertainties were calculated using the $s e_{d}$ and $s e_{p}$ values obtained from linear regression. The uncertainties in $\gamma_{S}{ }^{d}$ and $\gamma_{S}{ }^{p}$ are, respectively, equal to $2 s e_{d} \sqrt{\gamma_{S}{ }^{d}}$ and $2 s e_{p} \sqrt{\gamma_{S}{ }^{p}}$, and that in the total surface energy $\left(\gamma_{S}\right)$, is equal to $2 \sqrt{\left(s e_{d} \gamma_{S}^{d}\right)^{2}+\left(s e_{p} \gamma_{S}^{p}\right)^{2}}$.

In Figure 5, the contact angles calculated with the OWK surface energy parameters are plotted against the experimental $\theta_{a}$ values. The Pearson productmoment correlation coefficient was 0.7389 . Thus, a reasonable agreement between the experimental and predicted contact angles was observed.

The relative values of the surface energy components would be influenced by the surface concentrations of the polar (ammonium, sulfonate, or carboxylate ions, PEG segments, amide and ester groups, etc.) and nonpolar groups (perfluoroalkyl segments, styrene mers, etc.). From Table III, it is seen that the polar component of surface energy $\left(\gamma_{S}^{p}\right)$ was higher for the ionic polymers than for the nonionic polymers PS and PPFS. The total surface energies of BCs $2,3,4$, and 5 , on the basis of the $\theta_{a}$ values, were significantly lower than the surface energies of the zwitterionic homopolymers. The relatively low surface energy, calculated with $\theta_{a}$, was attributed to the fluoroalkyl groups present in these polymers. Martinelli et al. ${ }^{10}$ found that the fluoroalkyl groups lowered the surface energy significantly $\left(<20 \mathrm{~mJ} / \mathrm{m}^{2}\right)$, even when less than $10 \%$ of the mers were fluorinated. Hence, the $\theta_{a}$ values were not representative of the ionic composition of the zwitterionic and cationic BCs. The $\theta_{a}$ values were strongly influenced by the relatively small numbers of the highly nonpolar perfluoroalkyl groups in the BCs.
Table III also gives the surface energy of the ionic $\mathrm{BCs}$, determined with the $\theta_{r}$ values. These values were now closer to those of the zwitterionic homopolymers $\mathrm{P}(\mathrm{AAmPrDMAAc})$ and $\mathrm{P}(\mathrm{AAmPrDMAPS})$. Additionally, it was evident that the zwitterionic homopolymers had nearly the same surface energy, regardless of whether $\theta_{a}$ or $\theta_{r}$ was used for the surface energy determination. The same was true for the nonionic polymers PS and PPFS.

Thus, for the surfaces of the copolymers consisting of both polar and nonpolar mers, $\theta_{a}$ was determined primarily by the nonpolar mers, whereas $\theta_{r}$ was sensitive to the polar groups at the surface. For homopolymer surfaces, where mers of only one polarity were present, both the contact angles resulted in similar values of surface energy.

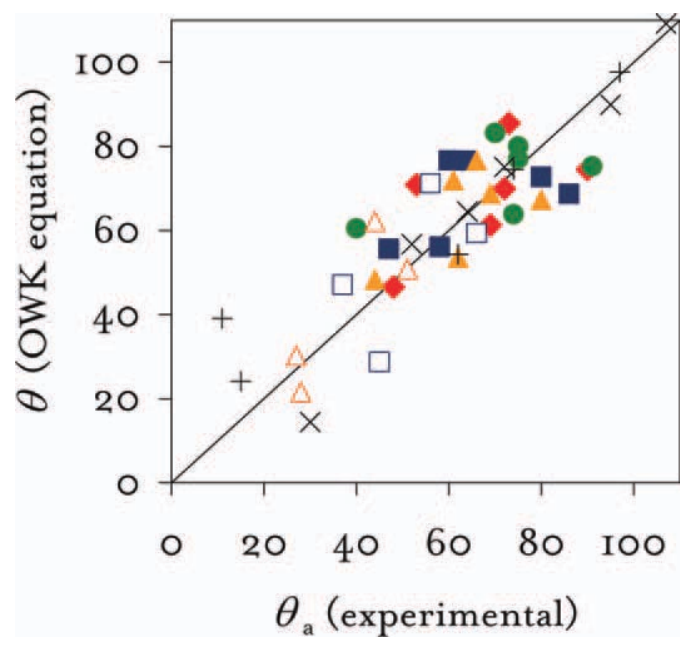

Figure 5 Contact angles calculated with the OWK model [eq. (3) and Table III] versus the experimental values for

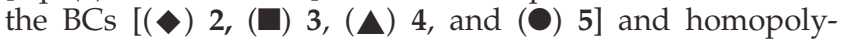
mers $[(\square) \mathrm{P}(\mathrm{AAmPrDMAAc}),(\triangle) \mathrm{P}(\mathrm{AAmPrDMAPS}),(+)$ PS, and $(x)$ PPFS]. [Color figure can be viewed in the online issue, which is available at wileyonlinelibrary.com.] 
The dispersion component of the surface energies $\left(\gamma_{S}{ }^{d}\right)$ of the carboxybetaine and sulfobetaine homopolymers, calculated with $\bar{\theta}$, were about 22 and 28 $\mathrm{mJ} / \mathrm{m}^{2}$, respectively, and the polar components $\left(\gamma_{S}{ }^{p \prime}\right.$ s) were about 45 and $38 \mathrm{~mJ} / \mathrm{m}^{2}$, respectively (cf. Table III). Hence, the total surface energy of $\mathrm{P}(\mathrm{AAmPrDMAPS})$ was close to that of $\mathrm{P}(\mathrm{AAmPrD}-$ MAAc) (ca. $66 \mathrm{~mJ} / \mathrm{m}^{2}$ ). The surface energy of the sulfobetaine homopolymer had a lower polar component than that of the carboxybetaine homopolymer; this was attributed to the presence of a greater number of the relatively nonpolar methylene groups between the ammonium ion and the sulfonate ion (three $-\mathrm{CH}_{2}-$ groups) in the sulfobetaine mer than that in the carboxybetaine mer (one $-\mathrm{CH}_{2}-$ group).

The contact angles and surface energy of PS determined in this work were in good agreement with literature values. ${ }^{54,55}$ We also determined the surface energy of PPFS, a polymer which has been widely investigated as an antibiofouling (fouling-release) polymer because of its low surface energy. The surface energy of this polymer was significantly lower than that of PS. Both PS and PPFS had negligible values of the polar surface energy component; this meant that mostly dispersion forces contributed to the work of adhesion on these surfaces.

The van Oss, Chaudhury, and Good and the Della-Volpe Siboni models ${ }^{56}$ were also used to estimate the surface energies of the ionic polymers. The results were qualitatively similar to those obtained with the OWK model and, hence, are not discussed in detail here.

\section{$\zeta$ potential and surface charge of the ionic BCs}

To determine the effect of $\mathrm{pH}$ on the net charge of the ionic $\mathrm{BCs}$, aqueous colloidal dispersions of the BCs were prepared. Because of the hydrophilicity of the ionic mers, we expected the ionic block to be preferentially present at the particle-water interface. The number-average particle diameters of the dispersions of the BCs P(AAmPrDMAAc- $r$ - $R_{f}$ PEGA)- $b$ PS, P(AAm PrDMAPS $r$ - $\left.\mathrm{R}_{\mathrm{f}} \mathrm{PEGA}\right)-b$-PS, and P(AAm PrDMABr- $r$ - $\mathrm{R}_{\mathrm{f}} \mathrm{PEGA}$ )- $b$-PS were $2.7,4.3$, and $2.3 \mu \mathrm{m}$, respectively. The particles were formed by the precipitation and aggregation of the BC chains in water. The particle sizes in coagulative nucleation, particularly in a surfactant-free system, are strongly sensitive to the surface charge density of the aggregates. ${ }^{57}$ The sulfobetaine moiety has two additional, relatively nonpolar $-\mathrm{CH}_{2}-$ groups in the zwitterionic structure. Subtle differences in the van der Waals and electrostatic forces between the different ionic groups in the polymer chains, mediated by the aqueous environment, could probably explain the observed difference in the particle diameters. The polarity of the water-miscible solvent THF, which

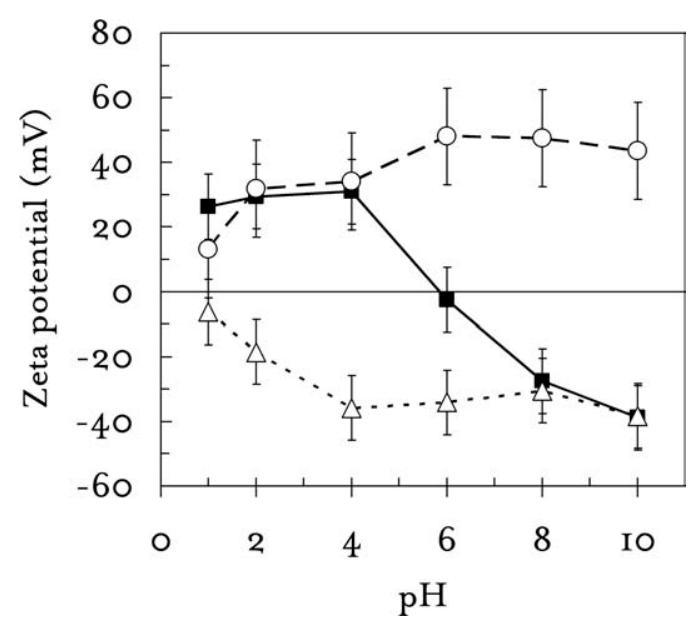

Figure $6 \quad \zeta$ potential of aqueous dispersions of the $(\square)$ $\mathrm{P}\left(\mathrm{AAmPrDMAAc}-r-\mathrm{R}_{\mathrm{f}} \mathrm{PEGA}\right)-b$-PS, $(\triangle) \mathrm{P}(\mathrm{AAmPrDMAPS}-$ $r$-R $\mathrm{PEGA})-b-\mathrm{PS}$, and $(\bigcirc) \mathrm{P}\left(\mathrm{AAmPrDMABr}-r-\mathrm{R}_{\mathrm{f}} \mathrm{PEGA}\right)-b-$ PS BCs $\left(T=25^{\circ} \mathrm{C}\right)$.

was used in particle formation, could also influence the particle size. A detailed investigation of these effects was beyond the scope of this study.

The sulfobetaine $\mathrm{BC}$ was found to be negatively charged over a pH range of 1-10 (cf. Fig. 6). This perhaps unexpected behavior of the zwitterionic sulfobetaine polymer as an anionic polymer can be understood on the basis of the strongly acidic nature of sulfonic acid (the conjugate acid of the sulfonate moiety present in the zwitterion) compared to carboxylic acid.

The net charge on the zwitterionic polymers is determined by the acid-base equilibria involving the tetraalkylammonium and sulfonate ions. Because of the strong acidity of sulfonic acid (e.g., $\mathrm{p} K_{a}$ of methanesulfonic acid $\approx-2.6$ ), almost all of the sulfonate would be present in the form of the anion, instead of the uncharged sulfonic acid [cf. eq. (7)]. Concomitantly, some of the tetraalkylammonium ion would associate with the $\mathrm{OH}^{-}$ions supplied by water to form uncharged tetraalkylammonium hydroxide [eq. (8), where $\mathrm{NR}_{4}^{+}=-\mathrm{CH}_{2} \mathrm{~N}^{+}\left(\mathrm{CH}_{3}\right)_{2} \mathrm{CH}_{2}-$ is the cationic group of the zwitterion]:

$$
\begin{gathered}
-\mathrm{CH}_{2} \mathrm{SO}_{3} \mathrm{H} \rightarrow-\mathrm{CH}_{2} \mathrm{SO}_{3}{ }^{-}+\mathrm{H}^{+} \\
\mathrm{NR}_{4}{ }^{+}+\mathrm{H}_{2} \mathrm{O} \stackrel{K_{h}}{\rightleftarrows} \mathrm{NR}_{4} \mathrm{OH} \mathrm{H}^{+}
\end{gathered}
$$

Because of an excess of the negatively charged sulfonate ion over the positively charged ammonium ion, the polymer would have an overall negative charge, as seen experimentally. For charge neutrality in the polymer, the $\mathrm{pH}$ must be lowered so that the equilibrium shown in eq. (8) is shifted to the left, in favor of $\mathrm{NR}_{4}{ }^{+}$formation. The decrease in the magnitude of surface charge with a decrease in $\mathrm{pH}$ and the approach toward the charge neutrality that is 
shown in Figure 6 are, thus, consistent with the proposed explanation. The equilibrium constant, $K_{h}$ [cf. eq. (8)], is related to the $\mathrm{pK}_{b}$ of $\mathrm{NR}_{4} \mathrm{OH}$ [cf. eq. (9)] by $\mathrm{p} K_{h}=14-\mathrm{p} K_{b}$ :

$$
\mathrm{NR}_{4} \mathrm{OH} \stackrel{K_{b}}{\rightleftarrows} \mathrm{NR}_{4}{ }^{+} \mathrm{OH}^{-}
$$

On the basis of the $\mathrm{pK} b$ of $\mathrm{NH}_{4} \mathrm{OH}(\approx 4.7)$, the value of $K_{h}$ is expected to be significant. The forward reaction of eq. (8) would therefore, result in a lowering of the isoelectric point of the sulfobetaine polymer. The experimentally observed acidity $(\mathrm{pH} \approx 2.6)$ of a solution of the cationic homopolymer poly[N-(3acrylamidopropyl)- $N, N$-dimethyl- $N$-(carbomethoxymethyl) ammonium bromide] [P(AAmPrDMABr)] in distilled water is also attributed to the hydrolysis reaction of the ammonium ion [cf. eq. (8)].

The situation is different in the case of the carboxybetaine group, which contained the carboxylate anion, the conjugate acid of which is relatively weak $\left(\mathrm{p} K_{a}\right.$ of acetic acid $\left.\approx 4.8\right)$. The almost irreversible reaction of eq. (7) is now replaced by the reversible reaction shown in eq. (10):

$$
-\mathrm{CH}_{2} \mathrm{COOH} \stackrel{K_{a}}{\rightleftarrows}-\mathrm{CH}_{2} \mathrm{COO}^{-}+\mathrm{H}^{+}
$$

When the $\mathrm{pH}$ is adjusted with a strong acid (e.g., $\mathrm{HCl}$ ) or base (e.g., $\mathrm{KOH})$, the fractions of the tetraalkylammonium hydroxide and the carboxylic acid groups that are in the dissociated form and, therefore, contribute to net charge are given by $1 /\left(1+10^{\mathrm{pH}-\mathrm{p} K_{h}}\right)$ and $1 /\left(1+10^{\mathrm{p} K_{a}-\mathrm{pH}}\right)$, respectively [cf. eqs. (9) and (10)]. ${ }^{58}$ At the isoelectric point, these fractions are equal. Hence, the isoelectric point of the zwitterion is given by $\mathrm{p} I=\left(\mathrm{p} K_{a}+\mathrm{p} K_{h}\right) / 2$. As expected, the experimentally observed isoelectric point of the carboxybetaine BC 3 was about 6 (Fig. 6), which is also in agreement with the results of another recent study. ${ }^{59}$

We believe that this is the first elucidation of the anionic behavior of sulfobetaine zwitterions with an analysis of ionic equilibria in zwitterionic systems. The negative $\zeta$ potentials of the sulfobetaine $\mathrm{BC}$ were in agreement with the observations of Graillat et al. ${ }^{60}$ that electrophoretic mobilities of PS latexes coated with (dodecyldimethylammonio)propanesulfonate sulfobetaine surfactant are negative at $\mathrm{pH}^{\prime}$ 's between 2 and 12. The nonexistence of an isoelectric point in the electrokinetic measurements of Graillat et al. ${ }^{60}$ could be rationalized with the explanation proposed herein.

The anionic character of the sulfobetaines was also consistent with the observations of Mary and Bendejacq, ${ }^{61}$ that the sulfobetaine polyzwitterions formed complexes only with positive polyelectrolytes (polycations) and not with polyanions of acrylic acid. Similarly, Polzer et al. ${ }^{62}$ recently reported a negative surface charge for colloidal particles consisting of a crosslinked PS core and a grafted poly(N-methyacryloxyethyl- $\mathrm{N}, \mathrm{N}$-dimethylammoniopropyl sulfonate) shell but attributed the negative charge to the potassium persulfate initiator and sodium dodecyl sulfate surfactant residues incorporated during the synthesis of the core particles. We expect that the sulfobetaine brushes would be negatively charged (at $\mathrm{pH} \geq$ 2) even if a nonionic initiator and surfactant were used because of the lowering of the isoelectric point of the sulfobetaine ampholyte caused by the hydrolysis reaction of the ammonium ion [cf. eq. (8)].

The hydrolysis of ester bonds, which would lead to the formation of the anionic carboxylic acid, could be argued to be a reason for the negative surface charge of the sulfobetaines. However, negligible hydrolysis would be expected during the synthesis of these polymers with the procedure outlined in Scheme 1 or during the $\zeta$-potential measurements. Moreover, each molecule of the cationic $N$-(3-acrylamidopropyl)- $N, N$-dimethyl- $N$-(carbomethoxymethy1)ammonium bromide (AAmPrDMABr) BC 5 contained a significantly higher number of ester groups than those of the zwitterionic BCs 3 and 4 (cf. Scheme 1 and Fig. 2), and yet, BC 5 showed positive surface charges in the electrokinetic measurements at $\mathrm{pH}$ values between 1 and 10. Thus, the primary reason for the anionic behavior of the sulfobetaine polymers was the relatively low isoelectric point of sulfobetaine.

It should be noted that $\mathrm{HCl}$ and $\mathrm{KOH}$ were used to adjust the $\mathrm{pH}$ of the dispersions. Any decrease in $\zeta$ potential at the $\mathrm{pH}$ extremes is also attributable to an increase in the ionic strength (due to the addition of acid or base that is required to cause the change in the $\mathrm{pH}$ ). Similarly, the dissociation constants, $K_{a}$ or $K_{b}$, could be different for monomers and polymers, because of local electrostatic interactions that are influenced by polymer conformation; but these differences are not expected to lead to discrepancies with the explanations presented herein.

Equation (11) gives the relation between the $\zeta$ potential and surface charge density $\left[\sigma\left(\mathrm{C} / \mathrm{m}^{2}\right)\right]$ for spherical particles of radius $a(\mathrm{~m})$ dispersed in a solution of a symmetric $1: 1$ electrolyte: $^{63}$

$$
\sigma=\frac{2 \varepsilon_{r} \varepsilon_{0} \kappa k T}{e} \sinh \left(\frac{e \zeta}{2 k T}\right)\left[1+\frac{1}{\kappa a} \frac{1}{\cosh ^{2}(e \zeta / 4 k T)}\right]
$$

where $\varepsilon_{r}$ is 78.54 for water at $25^{\circ} \mathrm{C}, \varepsilon_{0}$ is $8.85 \times 10^{-12}$ $\mathrm{C}^{2} \mathrm{~J}^{-1} \mathrm{~m}^{-1}, k$ is the Boltzmann constant $(1.38 \times$ $\left.10^{-23} \mathrm{~J} / \mathrm{K}\right), T$ is the absolute temperature $(\mathrm{K}), z$ is the valency of ions in the electrolyte, $e$ is the unit charge $\left(1.6 \times 10^{-19} \mathrm{C}\right), \kappa=\left[2000 M e^{2} N_{A} /\left(\varepsilon_{r} \varepsilon_{0} k T\right)\right]^{1 / 2}$ is the Debye-Hückel parameter, $M$ is the molarity $\left(\mathrm{mol} / \mathrm{dm}^{3}\right)$ of the electrolyte, and $N_{A}$ is the Avogadro's number $\left(6.023 \times 10^{23} \mathrm{~mol}^{-1}\right)$. When $\kappa a \gg 1$ (as 
TABLE IV

Sign of the Surface Charges of the Ionic BC Surfaces and BSA

\begin{tabular}{lcc}
\hline & PBS (pH 6.9) & MES (pH 3.5) \\
\hline P(DMAPrAAm- $r$-R REGA)- $b$-PS (2, precursor) $_{\mathrm{f}}$-R & + & + \\
P(AAmPrDMAAc- $r$ f PEGA)- $b$-PS (3, carboxybetaine) & - & + \\
P(AAmPrDMAPS- $r$ - $R_{\mathrm{f}}$ PEGA)- $b$-PS (4, sulfobetaine) & - & - \\
P(AAmPrDMABr- $r$ - $\mathrm{R}_{\mathrm{f}}$ PEGA)- $b$-PS (5, ammonium) & + & + \\
BSA & - & + \\
\hline
\end{tabular}

in our experiments) and $\zeta$ is less than about $100 \mathrm{mV}$, eq. (6) simplifies to $\sigma=0.117 \sqrt{M} \sinh \left(\frac{\zeta / \mathrm{mV}}{51.4}\right)$ at $25^{\circ} \mathrm{C}$. Thus, when the ionic strength is about $10 \mathrm{mM}$, a $\zeta$ potential of $40 \mathrm{mV}$ corresponds to a surface charge density of about $0.01 \mathrm{C} / \mathrm{m}^{2}$, which is relatively small, approximately one electronic charge per $16 \mathrm{~nm}^{2}$ of surface. A fully ionized surface, on the other hand, has one charge per $0.5 \mathrm{~nm}^{2}(\sigma=0.3 \mathrm{C} /$ $\left.\mathrm{m}^{2}\right) .{ }^{64}$ Thus, the ionic BC surfaces of this study were highly hydrophilic but with a relatively low surface charge density.

\section{Protein adsorption}

The influence of electrostatic interactions on the adsorption of positively and negatively charged protein molecules onto the ionic BC surfaces was studied by a comparison of the fluorescence intensities originating from adsorbed, fluorescently labeled probe protein molecules. The same protein was used, but we varied the net charge on the protein by changing the $\mathrm{pH}$ of the solution in which the adsorption occurred. BSA, a $66.8-\mathrm{kDa}$ protein, with 585 amino acid residues, an ellipsoidal shape of dimensions $14 \times 4 \times 4 \mathrm{~nm}^{3}$, and an isoelectric point of about 4.7 in water at $25^{\circ} \mathrm{C}$, was selected as a model protein for the study. Each polymer coating $\left(1.8 \times 1.8 \mathrm{~cm}^{2}\right)$ was incubated in about $2 \mathrm{~mL}$ of 1.5 $\mu M$ BSA-FITC solution. Protein solutions were prepared in PBS $(\mathrm{pH} \sim 6.9)$ and aqueous MES $(\mathrm{pH} \sim$ 3.5) to alter the net charge and the nature of electrostatic interaction between the protein and the surface.

Because BSA has an isoelectric point of 4.7, the protein molecules were expected to be negatively charged in PBS and positively charged in MES solution. Accordingly, the $\zeta$ potentials of BSA-FITC in PBS and MES solutions were found to be -28.0 and $27.4 \mathrm{mV}$, respectively, at $25^{\circ} \mathrm{C}$. The value of -28.0 $\mathrm{mV}$ in PBS was in good agreement with that reported by Kaufman et al. ${ }^{65}$ There was clearly an inversion in the net charge of the protein in moving from a $\mathrm{pH}$ above the isoelectric point to a $\mathrm{pH}$ below the isoelectric point. Table IV summarizes the nature of the charges on the BCs and BSA in the two solutions. The $\zeta$ potential of the $N$-(3-dimethylamino-1propyl)acrylamide BC precursor (polymer 2 ) was not determined, but on the basis of the relatively high $\mathrm{p} K_{a}$ of trimethylamine (9.74), it is expected that this polymer would carry a net positive charge in both the PBS and MES solutions. However, the surface charge density would be significantly lower than those on the ionic BC surfaces.

Figure 7 shows fluorescence images for the adsorption of BSA-FITC on the nonionic precursor $\mathrm{BC}$ 2, the zwitterionic BCs 3 and 4, the cationic BC 5, and the nonionic homopolymers PS and PPFS in PBS solution. A darker image corresponds to a lower fluorescence intensity and, hence, a lower adsorption of BSA-FITC. Several such images were analyzed for each polymer surface to obtain the mean fluorescence intensity reported in Figure 8. Figure 8 gives an average intensity over $300 \times 240 \times N$ pixels, where $N$ is the number of images analyzed. The intensities were normalized such that the average value for BSA-FITC adsorbed on PS in PBS corresponded to $100 \%$.

As expected, the hydrophobic PPFS and PS surfaces adsorbed relatively large concentrations of BSA. Protein adsorption on these nonionic surfaces was almost independent of the net charge on the protein molecules (cf. Fig. 8). The precursor BC 2 had almost the same amounts of adsorbed protein as the PS control. This polymer contained about $83 \mathrm{~mol} \% \mathrm{~N}$ (3-dimethylamino-1-propyl)acrylamide groups and 17 mol \% $\mathrm{R}_{\mathrm{f}}$ PEGA mers in the surface active block. Thus, it was evident that the small number of $R_{\mathrm{f}} \mathrm{PEG}$ groups in the precursor $\mathrm{BC}$ was unable to prevent protein adsorption at the surface of this polymer.

Quaternization reactions on the precursor $B C$ gave the hydrophilic zwitterionic BCs 3 and 4. In PBS solution, the adsorption of BSA was significantly lower on the surfaces of both 3 and 4 (the carboxybetaine and sulfobetaine $\mathrm{BCs}$, respectively) than PS. On the other hand, for the cationic BC 5, the surface density of adsorbed BSA was about two times that on PS (and about six times that on the zwitterionic coatings). The increased protein adsorption on the cationic polymer 5 and the BC precursor 2 could be attributed to electrostatic attraction between the negatively charged protein and the positively charged surface surface; see ref. 64). The lower BSA adsorption on the zwitterionic polymers was evidently due to a stronger net repulsive force between the polymer coatings and the protein. 


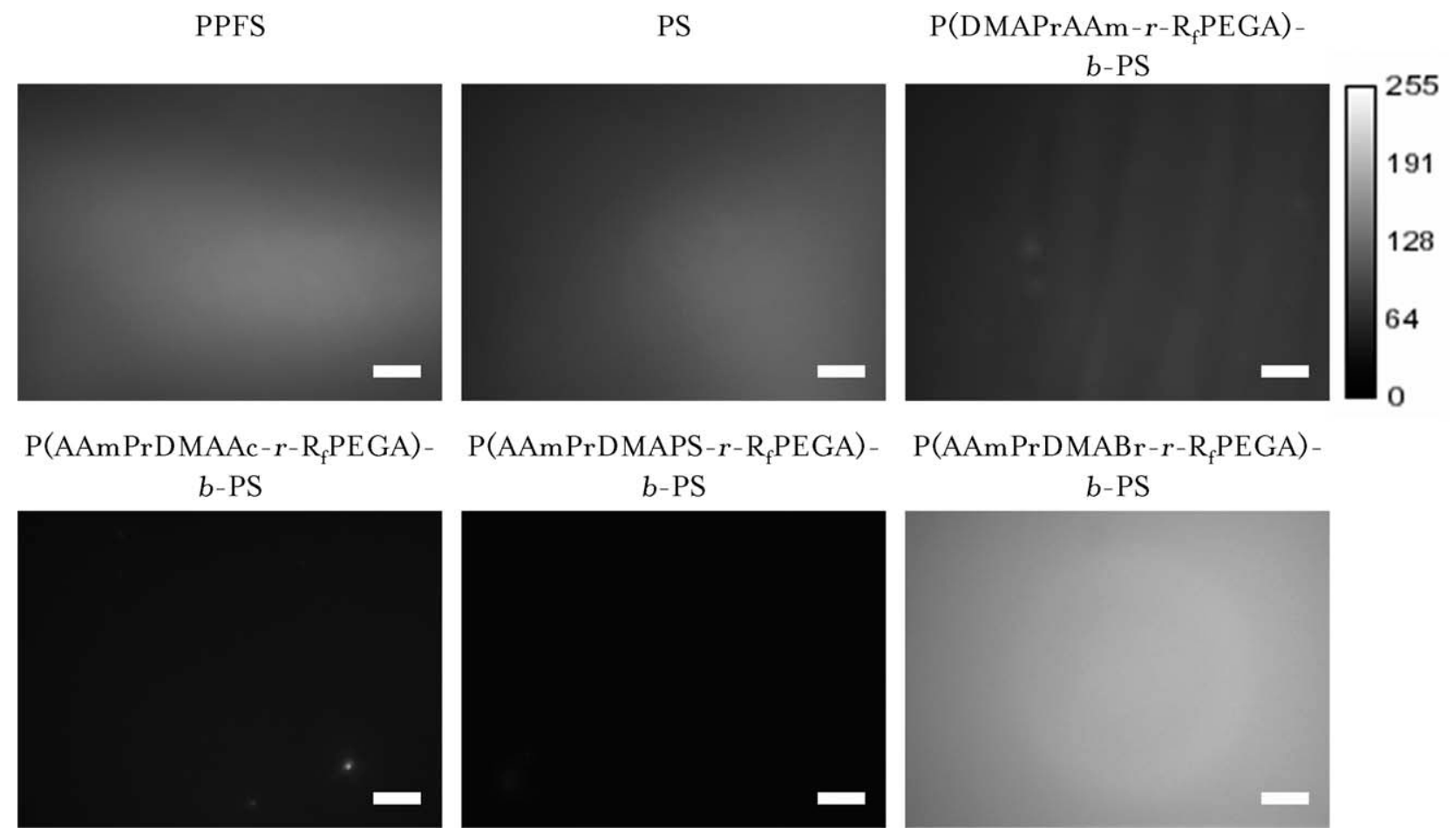

Figure 7 Fluorescence microscopy images of the polymer coatings with adsorbed BSA-FITC [adsorption in PBS of ionic strength $140 \mathrm{mM}$ (scale bar $=25 \mu \mathrm{m})]$.

In MES solution, the $\mathrm{pH}$ of the aqueous phase was below the isoelectric point of the protein, and the protein molecules had a net positive charge. The lower BSA adsorption on the positively charged BCs 3 and 5 compared to that on PS or PPFS was consistent with the expectation of repulsion between likecharged surfaces (the repulsive force between two similarly charged surfaces in a medium containing counterions is entropic in origin, not electrostaticthe electrostatic contribution to the net force is attractive even between two similarly charged surfaces; see ref. 64). The BSA adsorption on the negatively charged $\mathrm{P}$ (AAmPrDMAPS- $r$ - $\left.\mathrm{R}_{\mathrm{f}} \mathrm{PEGA}\right)-b$-PS (sulfobetaine) BC surface was higher in MES solution than in PBS solution yet lower than that on PS or PPFS. The higher protein adsorption in MES solution could be attributed to electrostatic attraction between the positively charged protein molecules and negatively charged BC surface. However, it was evident that electrostatic attraction (in PBS) was much stronger in the case of the cationic BC 5 than in that of the zwitterionic BC 4 (cf. Fig. 8).

An important inference from Figure 8 arises from a comparison of the adsorptions of (1) BSA-FITC on the sulfobetaine BC 4 in MES buffer and (2) BSAFITC on the cationic BC 5 in PBS. In both cases, the protein and the polymer surface were of opposite charges. However, the protein adsorption was significantly higher on the cationic polymer (case 2) than on the sulfobetaine polymer (case 1); this was attrib- uted to the stronger steric hydration forces on the zwitterionic polymer surface.

The formation of a hydration layer on a biomaterial surface and the resulting excluded volume interactions with hydrated protein molecules are responsible for the exclusion of protein from the surface of the biomaterial (see chapters 15 and 21 in ref. 64). The hydration shell consists of a layer of water molecules directly in contact with the surface. The disruption of a hydration shell consisting of strongly bound water is not energetically favorable. Repulsion occurs because of the energy needed to

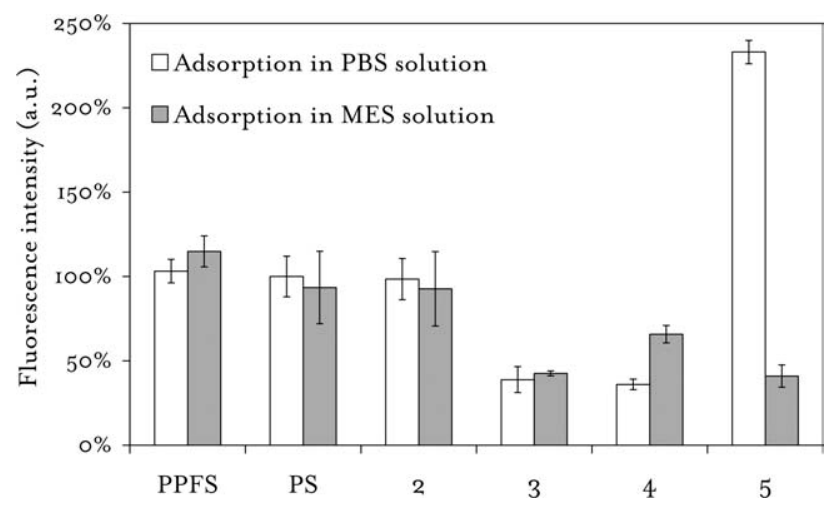

Figure 8 Relative adsorption of BSA-FITC from a $\mathrm{pH} 6.9$ PBS solution and a $\mathrm{pH}$ 3.5 MES solution on $\mathrm{P}(\mathrm{DMAPr}$ AAm- $r$ - $\left.\mathrm{R}_{\mathrm{f}} \mathrm{PEGA}\right)-b$-PS (2), P(AAmPrDMAAc- $r$ - $\left.\mathrm{R}_{\mathrm{f}} \mathrm{PEGA}\right)-b-$ PS (3), P(AAmPrDMAPS- $r$-R $\mathrm{f}$ PEGA)- $b$-PS (4), P(AAmPrDMABr- $\left.r-R_{\mathrm{f}} \mathrm{PEGA}\right)-b$-PS (5), PS, and PPFS. 
dehydrate the surface hydrophilic groups as the surfaces of the protein and the biomaterial approach each other.

West et al. ${ }^{66}$ performed a direct comparison of the antibioadherence of sulfobetaine and phosphobetaine random copolymer coatings and found that the phosphobetaine-based copolymer coatings were markedly superior to the sulfobetaine-based copolymer coatings; they attributed this to better hydration of the phosphobetaine head group (12-19 water molecules per head group) than of the sulfobetaine head group (8 water molecules).

It is expected that both types of zwitterionic groups in the $\mathrm{BCs}$ of this study would be highly hydrated. ${ }^{67}$ Furthermore, the extent of hydration would be higher in the case of the carboxybetaine side chains because of fewer methylene groups separating the ionic centers in these zwitterions. Moreover, the protein adsorption results indicated that the zwitterionic polymers were hydrated to a much greater extent than the cationic polymer. The relatively high adsorption of the negatively charged protein molecules on the cationic BC surface could be attributed to the layer of poorly hydrated bromide counterions on this surface. The cationic surface would be covered by an electrical double layer composed of bromide anions in the Stern layer (the first layer of the double layer). The bromide anion, because of its large size and weak electric field, would have a low hydration number $(\sim 1)$ in the aqueous phase. The relatively weak steric hydration force of the cationic BC surface would be unable to overcome the force of electrostatic interaction, resulting in the highest protein adsorption on this surface (cf. Fig. 8). Thus, the steric hydration forces on protein repulsion decreased in the following order: carboxybetaine $\geq$ sulfobetaine $\geq$ cationic.

\section{CONCLUSIONS}

We have discussed a simple polymer analogous reaction strategy for the synthesis of surface-active ionic BCs that can form water-insoluble antifouling coatings on surfaces by techniques such as dip coating, spin coating, and spraying. All of the ionic BC surfaces were found to be quite hydrophilic, as expected. The total surface energies of the carboxybetaine and sulfobetaine homopolymers were both about $66 \mathrm{~mJ} / \mathrm{m}^{2}$. The total surface energies of the zwitterionic BC coatings, calculated with the $\theta_{r}$ values, were also about $66 \mathrm{~mJ} / \mathrm{m}^{2}$; this indicated that the zwitterionic moieties were present at the surface, despite their high surface energy.

All of the ionic polymers possessed net charges and nonzero electrophoretic mobilities in aqueous dispersions (except at the isoelectric $\mathrm{pH} \mathrm{6,} \mathrm{at} \mathrm{which}$ the carboxybetaine polymer had no net charge). Contrary to the notion that sulfobetaines should exhibit charge neutrality because of their zwitterionic nature, the sulfobetaine BC surfaces were found to be negatively charged throughout the $\mathrm{pH}$ range of $2-10$.

Both the zwitterionic coatings, including the negatively charged sulfobetaine surface, showed low protein adsorption regardless of the net charges on the protein molecules or the polymer coatings. In contrast, the amount of protein adsorbed on the cationic BC surface was strongly dependent on protein charge. The protein resistance of the zwitterionic BC surfaces was attributed to steric hydration repulsion forces. The hydration force was weaker in the cationic BC surface because of the presence of free bromide counterions, which were poorly hydrated. Thus, the zwitterionic polymers of this study are expected to be effective in preventing adsorption of protein molecules with isoelectric points both below and above the physiological $\mathrm{pH}$ (ca. 7.4) or the $\mathrm{pH}$ of seawater (ca. 8.0), so they could be used as biocompatible coatings for biomedical applications and as marine antifouling coatings.

The authors made use of research facilities at the Center for Advanced Materials Processing at Clarkson University, which was supported by the New York State Office of Science, Technology, and Academic Research. They thank Stefan Grimberg for the use of the fluorescence microscope in his laboratory and Tereza Paronyan for assistance in acquiring the XPS spectra at the Conn Center for Renewable Energy Research (University of Louisville). The authors also thank Sumona Mondal for discussions on the normal probability plot of residuals and multicollinearity in the multiple linear regression analysis used in this work.

\section{References}

1. Krishnan, S.; Weinman, C. J.; Ober, C. K. J Mater Chem 2008, $18,3405$.

2. Vendra, V. K.; Wu, L.; Krishnan, S. In Nanostructured Thin Films and Surfaces, Kumar, C., Ed.; Wiley-VCH: Weinheim, Germany, 2010, Chap. 1.

3. Weinman, C. J.; Gunari, N.; Krishnan, S.; Dong, R.; Paik, M. Y.; Sohn, K. E.; Walker, G. C.; Kramer, E. J.; Fischer, D. A.; Ober, C. K. Soft Matter 2010, 6, 3237.

4. Weinman, C. J.; Finlay, J. A.; Park, D.; Paik, M. Y.; Krishnan, S.; Sundaram, H. S.; Dimitriou, M.; Sohn, K. E.; Callow, M. E.; Callow, J. A.; Handlin, D. L.; Willis, C. L.; Kramer, E. J.; Ober, C. K. Langmuir 2009, 25, 12266.

5. Park, D.; Finlay, J. A.; Ward, R. J.; Weinman, C. J.; Krishnan, S.; Paik, M.; Sohn, K. E.; Callow, M. E.; Callow, J. A.; Handlin, D. L.; Willis, C. L.; Fischer, D. A.; Angert, E. R.; Kramer, E. J.; Ober, C. K. Am Chem Soc Appl Mater Interfaces 2010, 2, 703.

6. Yang, R.; Xu, J.; Ozaydin-Ince, G.; Wong, S. Y.; Gleason, K. K. Chem Mater 2011, 23, 1263.

7. Su, Y.-L.; Cheng, W.; Li, C.; Jiang, Z. J Membr Sci 2009, 329, 246.

8. Anjum, N.; Bellon-Fontaine, M. N.; Herry, J. M.; Riquet, A. M. J Appl Polym Sci 2008, 109, 1746. 
9. Krishnan, S.; Ayothi, R.; Hexemer, A.; Finlay, J. A.; Sohn, K. E.; Perry, R.; Ober, C. K.; Kramer, E. J.; Callow, M. E.; Callow, J. A.; Fischer, D. A. Langmuir 2006, 22, 5075.

10. Martinelli, E.; Menghetti, S.; Galli, G.; Glisenti, A.; Krishnan, S.; Paik, M. Y.; Ober, C. K.; Smilgies, D. M.; Fischer, D. A. J Polym Sci Part A: Polym Chem 2009, 47, 267.

11. Krishnan, S.; Wang, N.; Ober, C. K.; Finlay, J. A.; Callow, M. E.; Callow, J. A.; Hexemer, A.; Sohn, K. E.; Kramer, E. J.; Fischer, D. A. Biomacromolecules 2006, 7, 1449.

12. Krishnan, S.; Ward, R. J.; Hexemer, A.; Sohn, K. E.; Lee, K. L.; Angert, E. R.; Fischer, D. A.; Kramer, E. J.; Ober, C. K. Langmuir 2006, 22, 11255.

13. Kane, R. S.; Deschatelets, P.; Whitesides, G. M. Langmuir 2003, 19, 2388.

14. Emmenegger, C. R.; Brynda, E.; Riedel, T.; Sedlakova, Z.; Houska, M.; Alles, A. B. Langmuir 2009, 25, 6328.

15. Hayward, J. A.; Chapman, D. Biomaterials 1984, 5, 135.

16. Murphy, E. F.; Lu, J. R.; Brewer, J.; Russell, J.; Penfold, J. Langmuir 1999, 15, 1313.

17. Nguyen, A. T.; Baggerman, J.; Paulusse, J. M. J.; van Rijn, C. J. M.; Zuilhof, H. Langmuir 2011, 27, 2587.

18. Cho, W. K.; Kong, B.; Choi, I. S. Langmuir 2007, 23, 5678.

19. Chen, S.; Jiang, S. Adv Mater 2008, 20, 335.

20. Zhang, Z.; Chao, T.; Chen, S. F.; Jiang, S. Langmuir 2006, 22, 10072.

21. Chiang, Y. C.; Chang, Y.; Higuchi, A.; Chen, W. Y.; Ruaan, R. C. J Membr Sci 2009, 339, 151.

22. Zhao, Y. H.; Wee, K. H.; Bai, R. J Membr Sci 2010, 362, 326.

23. Ladd, J.; Zhang, Z.; Chen, S.; Hower, J. C.; Jiang, S. Biomacromolecules 2008, 9, 1357.

24. Zhang, Z.; Finlay, J. A.; Wang, L. F.; Gao, Y.; Callow, J. A.; Callow, M. E.; Jiang, S. Y. Langmuir 2009, 25, 13516.

25. Roth, C. M.; Lenhoff, A. M. Langmuir 1993, 9, 962.

26. Kato, K.; Sano, S.; Ikada, Y. Colloid Surface B 1995, 4, 221.

27. Wittemann, A.; Haupt, B.; Ballauff, M. Phys Chem Chem Phys 2003, 5, 1671.

28. Carlsson, F.; Hyltner, E.; Arnebrant, T.; Malmsten, M.; Linse, P. J Phys Chem B 2004, 108, 9871.

29. Brzozowska, A. M.; Hofs, B.; de Keizer, A.; Fokkink, R.; Stuart, M. A. C.; Norde, W. Colloid Surf A 2009, 347, 146.

30. Czeslik, C.; Jackler, G.; Steitz, R.; von Grunberg, H. H. J Phys Chem B 2004, 108, 13395.

31. Patil, S.; Sandberg, A.; Heckert, E.; Self, W.; Seal, S. Biomaterials 2007, 28, 4600 .

32. Rezwan, K.; Meier, L. P.; Rezwan, M.; Vörös, J.; Textor, M.; Gauckler, L. J. Langmuir 2004, 20, 10055.

33. Castelletto, V.; Krysmann, M.; Kelarakis, A.; Jauregi, P. Biomacromolecules 2007, 8, 2244.

34. Salgin, S.; Takaç, S.; Özdamar, T. H. J Membr Sci 2006, 278, 251.

35. Luo, N.; Zhang, C.; Hirt, D. E.; Husson, S. M. Colloids Surf B 2006, 50, 89.

36. Gon, S.; Santore, M. M. Langmuir 2011, 27, 1487.

37. Delgado, A. V.; González-Caballero, F.; Hunter, R. J.; Koopal, L. K.; Lyklema, J. J Colloid Interface Sci 2007, 309, 194.

38. Park, M. K.; Youk, J. H.; Pispas, S.; Hadjichristidis, N.; Advincula, R. Langmuir 2002, 18, 8040.

39. Thanawala, S. K.; Chaudhury, M. K. Langmuir 2000, 16, 1256.
40. Koberstein, J. T. J Polym Sci Part B: Polym Phys 2004, 42, 2942.

41. Krishnan, S.; Paik, M. Y.; Ober, C. K.; Martinelli, E.; Galli, G.; Sohn, K. E.; Kramer, E. J.; Fischer, D. A. Macromolecules 2010, $43,4733$.

42. Kudaibergenov, S.; Jaeger, W.; Laschewsky, A. In Supramolecular Polymers Polymeric Betains Oligomers; Springer: Berlin, 2006; p 157.

43. Thomas, D. B.; Vasilieva, Y. A.; Armentrout, R. S.; McCormick, C. L. Macromolecules 2003, 36, 9710.

44. Holmlin, R. E.; Chen, X.; Chapman, R. G.; Takayama, S.; Whitesides, G. M. Langmuir 2001, 17, 2841.

45. Nagaya, J.; Uzawa, H.; Minoura, N. Macromol Rapid Commun 1999, 20, 573.

46. Sundaram, H. S.; Cho, Y.; Weinman, C. J.; Paik, M. Y.; Dimitriou, M. D.; Finlay, J. A.; Callow, M. E.; Callow, J. A.; Kramer, E. J.; Ober, C. K. Polym Prepr (Am Chem Soc Div Polym Chem) 2010, 51, 384.

47. Liaw, D. J.; Huang, C. C.; Lee, W. F.; Borbely, J.; Kang, E. T. J Polym Sci Part A: Polym Chem 1997, 35, 3527.

48. Ratner, B.; Castner, D. In Surface Analysis: The Principal Techniques; Vickerman, J. C., Ed.; Wiley: New York, 2004.

49. Hiwatashi, T.; Hayama, K.; Sawada, Y.; Itoh, T. J Appl Polym Sci 2005, 98, 1235.

50. Khandwekar, A. P.; Doble, M.; Patil, D. P.; Shouche, Y. S. J Biomater Appl 2010, 25, 119.

51. Carré, A. J Adhes Sci Technol 2007, 21, 961.

52. Smith, R.; Pitrola, R. J Appl Polym Sci 2002, 83, 997.

53. Della Volpe, C.; Maniglo, D.; Siboni, S.; Morra, M. J Adhes Sci Technol 2003, 17, 1477.

54. Ellison, A. H.; Zisman, W. A. J Phys Chem 1954, 58, 503.

55. Kwok, D. Y.; Lam, C. N. C.; Li, A.; Zhu, K.; Wu, R.; Neumann, A. W. Polym Eng Sci 1998, 38, 1675.

56. Della Volpe, C.; Siboni, S. J Adhes Sci Technol 2000, 14, 235.

57. Krishnan, S.; Klein, A.; El-Aasser, M. S.; Sudol, E. D. Macromolecules 2003, 36, 3152.

58. Sandler, S. I. In Chemical, Biochemical, and Engineering Thermodynamics; Wiley: Hoboken, NJ, 2006.

59. Abraham, S.; Unsworth, L. D. J Polym Sci Part A: Polym Chem 2011, 49, 1051.

60. Graillat, C.; Dumont, B.; Depraetere, P.; Vintenon, V.; Pichot, C. Langmuir 1991, 7, 872.

61. Mary, P.; Bendejacq, D. D. J Phys Chem B 2008, 112, 2299.

62. Polzer, F.; Heigl, J.; Schneider, C.; Ballauff, M.; Borisov, O. V. Macromolecules 2011, 44, 1654.

63. Makino, K.; Ohshima, H. Langmuir 2010, 26, 18016.

64. Israelachvili, J. N. In Intermolecular and Surface Forces; Academic: Burlington, MA, 2011.

65. Kaufman, E. D.; Belyea, J.; Johnson, M. C.; Nicholson, Z. M.; Ricks, J. L.; Shah, P. K.; Bayless, M.; Pettersson, T.; Feldotö, Z.; Blomberg, E.; Claesson, P.; Franzen, S. Langmuir 2007, 23, 6053.

66. West, S. L.; Salvage, J. P.; Lobb, E. J.; Armes, S. P.; Billingham, N. C.; Lewis, A. L.; Hanlon, G. W.; Lloyd, A. W. Biomaterials 2004, 25, 1195.

67. Shao, Q.; He, Y.; White, A. D.; Jiang, S. J Phys Chem B 2010, 114,16625 . 